\title{
Backbone NMR reveals allosteric signal transduction networks in the $\beta_{1^{-}}$ adrenergic receptor
}

Shin Isogai ${ }^{1}$, Xavier Deupi ${ }^{2}$, Christian Opitz ${ }^{1}$, Franziska M. Heydenreich ${ }^{2}$, Ching-Ju Tsai $^{2}$, Florian Brueckner ${ }^{2}$, Gebhard F.X. Schertler ${ }^{2,3 *}$, Dmitry B. Veprintsev ${ }^{2,3 *}$ and Stephan Grzesiek ${ }^{1, *}$

${ }^{1}$ Focal Area Structural Biology and Biophysics, Biozentrum, University of Basel, CH-4056 Basel, Switzerland

${ }^{2}$ Paul Scherrer Institute, CH-5232 Villigen PSI, Switzerland

${ }^{3}$ Department of Biology, ETH Zurich, CH-8093 Zurich, Switzerland

*corresponding authors

Stephan Grzesiek

Focal Area Structural Biology and Biophysics, Biozentrum

University of Basel, CH-4056 Basel, Switzerland

Phone: $\quad++41612672100$

FAX: $\quad++41612672109$

Email: Stephan.Grzesiek@unibas.ch

Dmitry B. Veprintsev

Paul Scherrer Institute, CH-5232 Villigen PSI, Switzerland

Email: dmitry.veprintsev@psi.ch

Gebhard F.X. Schertler

Paul Scherrer Institute, CH-5232 Villigen PSI, Switzerland

Email: gebhard.schertler@psi.ch 


\section{Introduction}

G protein-coupled receptors (GPCRs) are physiologically important transmembrane signaling proteins that trigger intracellular responses upon binding of extracellular ligands. Despite recent breakthroughs in GPCR crystallography ${ }^{1-3}$, the details of ligand-induced signal transduction are not well understood due to missing dynamical information. In principle, such information can be provided by $\mathrm{NMR}^{4}$, but so far only limited data of functional relevance on few side chain sites of eukaryotic GPCRs have been obtained ${ }^{5-9}$. Here, we show that receptor motions can be followed at virtually any backbone site in a thermostabilized mutant of the turkey $\beta_{1}$-adrenergic receptor $\left(\beta_{1} \mathrm{AR}\right)^{10-12}$. Labeling with ${ }^{15} \mathrm{~N}$-valine in a eukaryotic expression system provides over twenty resolved resonances that report on structure and dynamics in six ligand complexes and the apo form. The response to the various ligands is heterogeneous in the vicinity of the binding pocket, but gets transformed into a homogeneous readout at the intracellular side of helix 5 (TM5), which correlates linearly with ligand efficacy for the G protein pathway. The effect of several pertinent, thermostabilizing point mutations was assessed by reverting them to the native sequence. Whereas the response to ligands remains largely unchanged, binding of the $\mathrm{G}$ protein mimetic nanobody NB80 and G protein activation are only observed when two conserved tyrosines (Y227 and Y343) are restored. Binding of NB80 leads to very strong spectral changes throughout the receptor including the extracellular ligand entrance pocket. This indicates that even the fully thermostabilized receptor undergoes activating motions in TM5, but the fully active state is only reached in presence of Y227 and Y343 by stabilization with a $G$ protein-like partner. The combined analysis of chemical shift changes from the point mutations and ligand responses identifies crucial connections in the allosteric activation pathway and presents a general experimental method to delineate signal transmission networks at high resolution in GPCRs. 


\section{Results and discussion}

A thermostabilized, detergent-resistant mutant of $\beta_{1} \mathrm{AR}^{10-12}$ (TS- $\beta_{1} \mathrm{AR}$; see Methods) was selectively labeled with ${ }^{15} \mathrm{~N}$ valine and produced in insect cells without further chemical modifications. Its 28 valine residues are homogeneously distributed across the receptor (Extended Data Figure 1) at locations suitable to sense ligand binding and receptor activation. Although resonances of main chain atoms are considerably more difficult to observe than those of mobile side chains of surface residues, they are expected to be better reporters of functional, long-range backbone motions. We succeeded to obtain well-resolved TROSY spectra of the valine ${ }^{1} \mathrm{H}-{ }^{15} \mathrm{~N}$ backbone resonances of detergent-solubilized TS- $\beta_{1}$ AR in its apo form and in complexes with six ligands (Extended Data Figure 1) ranging in their efficacy from antagonists to agonists (Extended Data Table 1). Despite the absence of deuteration and very short $\mathrm{T}_{2}$ relaxation times $\left(\sim 4 \mathrm{~ms}\right.$ for $\left.{ }^{1} \mathrm{H}^{\mathrm{N}}\right), 26$ valine resonances could be observed with sufficient sensitivity and resolution. Distinct and reversible chemical shift changes were detected for many valines after ligand exchange. 16 valines were assigned unambiguously and 5 tentatively using spectra from 18 point mutants, as well as further spectral and structural information (Extended Data Table 2).

Many valine residues in the vicinity of the ligand binding pocket could be assigned, showing chemical shift changes that report on the ligand functional groups (Figure 1). Remarkably, residue V172(4.56) (the number in parenthesis corresponds to the BallesterosWeinstein numbering system ${ }^{13}$ ), which is located close to the ligand aromatic head group, exhibits an unusual ${ }^{15} \mathrm{~N}$ chemical shift of $\sim 105-110 \mathrm{ppm}$ (Extended Data Figure 1, 2 and Figure 1C). This anomaly seems caused by a distorted backbone geometry, which is presumably conserved among adrenergic receptors and results from a missing hydrogen bond to the proline at position 176(4.60) (Extended Data Figure 2). Instead, the carbonyl of V172(4.56) participates in a water-mediated hydrogen bond network, which connects the ligand binding site, TM3, TM4, TM5, and TM6 $6^{12,14}$. Seemingly as a result of these interactions, the V172(4.56) ${ }^{1} \mathrm{H}^{-15} \mathrm{~N}$ resonances cluster according to the substitution patterns of the ligand head group (Figure 1C): one cluster is observed for the partial agonists/antagonists cyanopindolol, alprenolol and carvedilol, which have larger head groups with ortho- and/or meta-substitutions; a second cluster is observed for the agonists isoprenaline and dobutamine, which bear a meta- and para-substituted catechol ring. We attribute the distinct chemical shifts for isoprenaline or dobutamine to the loss of a coordinated water caused by specific hydrogen bond interactions between their catechol moieties and the side chain of S215(5.461) (Extended Data Figure 2D). 
Remarkably, the resonance positions of V172(4.56) in complex with the antagonist atenolol strongly differ from the already described complexes and the apo form: considerable ${ }^{1} \mathrm{H}^{\mathrm{N}}(>0.4 \mathrm{ppm})$ and ${ }^{15} \mathrm{~N}(>4 \mathrm{ppm})$ upfield shifts indicate, respectively, a further weakening of the main chain hydrogen bond $\mathrm{V} 172(4.56) \mathrm{H}^{\mathrm{N}} \cdots \mathrm{I} 168(4.52) \mathrm{O}$ and a stronger kink of the backbone. This rearrangement is likely due to the "insertion" of the para-acetamide group of the ligand head between residues S215(5.461) and V172(4.56) (Extended Data Figure 2D). This will lead to a substantial disruption of the TM3-TM4-TM5 interface, thereby precluding receptor activation, in agreement with atenolol's inverse agonist pharmacology. Thus, the amide chemical shifts of V172(4.56) constitute a very sensitive readout for the state of this water-mediated, inter-helical activation switch.

The ${ }^{1} \mathrm{H}-{ }^{15} \mathrm{~N}$ chemical shifts of further residues in the vicinity of the binding pocket report on additional characteristics of the ligands. V314(6.59) and V202(ECL2) are located at the extracellular surface of the receptor in a "vestibule" next to the entry/exit pathway of the orthosteric binding site ${ }^{15,16}$. The resonances of these residues are either severely broadened or undetectable in the absence of ligands, whereas they are observable in the presence of ligands (Figure 1D and Extended Data Figure 3). A line shape analysis for V314(6.59) (Extended Data Figure 4) indicates that this extracellular part of the receptor undergoes micro- to millisecond motions in the apo form, which are quenched by ligand binding. This is consistent with results on $\beta_{2} \mathrm{AR}$, which suggest that high-affinity ligands stabilize the conformation of ECL2 and ECL $3^{5}$. The ligand-induced shifts of the V314 resonance correlate strongly $\left(r^{2}=0.95\right)$ with the reported ligand affinity ${ }^{17}$ (Figure 1D). Interestingly, the resonances of V314(6.59) in the apo form and in high-affinity ligand complexes are very close. This may indicate that the highaffinity ligand complexes mimic the average apo conformation. Finally, the ${ }^{1} \mathrm{H}-{ }^{15} \mathrm{~N}$ chemical shifts of V125(3.36) at the bottom of the binding site and of V103(2.65) close to the ligand tail reveal additional trends (Figure 1E): the chemical shifts of V125 correlate with the depth of ligand insertion towards the central part of TM3 $\left(r^{2}=0.81\right)$, whereas those of V103 correlate with the volume of the ligand tail $\left(r^{2}=0.90\right)$.

As compared to inactive $\beta_{2} \mathrm{AR}$, complexes of activated $\beta_{2} \mathrm{AR}$ with either $\mathrm{G}$ protein ${ }^{2}$ or the G protein-mimicking nanobody NB80,18 show large movements at the intracellular sides of TM5, TM6 and their intervening loop ICL3, which form the binding site for the Grotein. These conformational changes are expected to be conserved throughout the GPCR family ${ }^{19}$. Four valine residues could be assigned in this region of TS- $\beta_{1}$ AR: V226(5.57), V230(5.61), V280(6.25), and V298(6.43) (Figure 2). In contrast to the chemical shift changes in the 
vicinity of the ligand binding pocket, which depend strongly on the ligand chemistry, the shifts of the TM5 residues observed in this region report on ligand efficacy. This effect is most prominent for residue V226(5.57), for which the ${ }^{1} \mathrm{H}-{ }^{15} \mathrm{~N}$ resonances fall on one line from antagonists to agonists (Figure 2A). The chemical shifts for the different ligands correlate very strongly $\left(r^{2}=0.89\right)$ with their reported ${ }^{17}$ efficacies for Gs signaling (Extended Data Table 1). This highly linear effect suggests that the receptor filters the diverse input signals from the various ligands to a unified and precise structural response on TM5, which can be read out by the chemical shifts of V226(5.57). Interestingly, the V226(5.57) atenolol peak is situated at a position corresponding to lower efficacy than for the apo receptor. This gives direct structural evidence of atenolol's inverse agonist action, which reduces the activation relative to the basal level of the apo receptor.

Current high-resolution structures of $\beta_{1} \mathrm{AR}$ do not show significant changes between antagonist- and agonist-bound forms (Figure 2B, top panel). The decrease of the V226(5.57) ${ }^{1} \mathrm{H}^{\mathrm{N}}$ chemical shift by about $0.2 \mathrm{ppm}$ from the agonist isoprenaline to the antagonist atenolol indicates a lengthening of the V226(5.57)- $\mathrm{H}^{\mathrm{N}} \cdots \mathrm{I} 222(5.53)$-O hydrogen bond by about $0.05 \AA^{20}$. This small, but clearly NMR-detectable length variation is below the resolution limit of current GPCR structures (Supplementary Information Text 1), but may indicate the start of TM5 bending towards the active conformation as observed in the $G$ protein-bound form of $\beta_{2} \mathrm{AR}$ (Figure 2B). Remarkably, this response to agonists occurs even in the thermostabilized receptor TS- $\beta_{1} \mathrm{AR}$. Albeit reduced in absolute size as compared to V226(5.57), V230(5.61) displays similar linear chemical shift changes as a function of ligand efficacy for the Gs pathway (Figure 2C). As this residue is located one helical turn further towards the cytoplasm, the detected conformational change is not just local, but spans a certain length in TM5.

Compared to V226(5.57) and V230(5.61) in TM5, the chemical shift response to ligands is much less pronounced for V298(6.43) and in particular V280(6.25) at the intracellular side of TM6 (Figure 2C). This suggests that agonist binding to the TS- $\beta_{1} \mathrm{AR}$ does not induce the large conformational change in TM6 observed in the activated $\beta_{2} \mathrm{AR}-\mathrm{G}-$ protein ${ }^{2}$ or $\beta_{2} \mathrm{AR}$ NB80 ${ }^{18}$ complexes. However, G protein activation upon agonist binding has been reported for other less thermostabilized $\beta_{1} \mathrm{AR}$ constructs ${ }^{17}$, indicating that they can still be activated, albeit at low levels. Thus we reverted the mutations most likely to interfere with the activation mechanism in TS- $\beta_{1} \mathrm{AR}$, i.e. I129(3.40)V in the connector switch ${ }^{15}$, Y227(5.58)A in TM5 ${ }^{21,22}$, and Y343(7.53)L in the NPxxY motif of TM7 $7^{14,22}$ to the native residues. These reverse mutants were then tested for G protein activation and the NMR response in TM6. A summary of the 
results is given in Extended Data Table 3. The original TS- $\beta_{1} \mathrm{AR}$, the single mutants TS$\beta_{1} \mathrm{AR}_{\mathrm{V} 129 \mathrm{I}}$, TS- $\beta_{1} \mathrm{AR}_{\mathrm{A} 227 \mathrm{Y}}$, and TS- $\beta_{1} \mathrm{AR}_{\mathrm{L} 343 \mathrm{Y}}$ as well as the double mutant TS- $\beta_{1} \mathrm{AR}_{\mathrm{V} 1291 / \mathrm{A} 227 \mathrm{Y}}$ showed no detectable G protein activation upon isoprenaline binding (Extended Data Figure 5). However, $G$ protein activation was detectable for the least thermostable $T S-\beta_{1} A_{A} R_{A 227 / L 343 Y}$ double mutant $\left(\mathrm{T}_{\mathrm{m}}\right.$ reduced by $11{ }^{\circ} \mathrm{C}$ relative to TS- $\left.\beta_{1} \mathrm{AR}\right)$, which recovers the conserved tyrosines in TM5 and TM7 that are known to stabilize the active state of rhodopsin ${ }^{22}$. None of the reverse mutants showed major changes in the NMR spectra of various ligand complexes as compared to the original TS- $\beta_{1} \mathrm{AR}$ (Extended Data Figure 6). In particular, residues V298(6.43) and V280(6.25) at the intracellular side of TM6 did not show an increased response to agonists. This is in agreement with recent DEER and ${ }^{19} \mathrm{~F}-\mathrm{NMR}$ data showing that agonists alone do not fully stabilize the active state of TM6 in $\beta_{2} \mathrm{AR}^{9}$. Interestingly, the V129(3.40)I and the V129(3.40)I/A227(5.58)Y mutations shifted the ${ }^{1} \mathrm{H}-{ }^{15} \mathrm{~N}$ resonances of V226(5.57) towards a more active (i.e. bent) state of TM5 in both the atenonol- and isoprenaline-bound forms (Extended Data Figure 6B), thereby given direct experimental evidence for an allosteric activation pathway spanning about $13 \AA$ from I129(3.40) on TM3 to V226(5.57) on TM5.

With the exception of rhodopsin ${ }^{23}$, the stabilization of fully active GPCR conformations seems to require binding of an agonist and an intracellular partner ${ }^{8.9}$. Indeed, when both the agonist isoprenaline and the $\mathrm{G}$ protein-mimicking nanobody $\mathrm{NB} 80^{18}$ were added to TS$\beta_{1} \mathrm{AR}_{\mathrm{A} 227 \mathrm{Y} / \mathrm{L} 343 \mathrm{Y}}$, very large chemical shift responses for many valine residues in TM3-6 were observed, whereas no change was observed for several valines in TM1, 2, and 7 (Extended Data Figure 7). This very strong response extends even to the extracellular residue V314(6.59), providing evidence of a long-distance connection from the G protein binding site to the ligand entry site. The strong chemical shift changes are reverted when the partial agonist/antagonist cyanopindolol is added to the isoprenaline-TS- $\beta_{1} \mathrm{AR}_{\mathrm{A} 227 \mathrm{Y} / \mathrm{L} 343 \mathrm{Y}}-\mathrm{NB} 80$ complex. The spectrum then becomes identical to that of the "pure" cyanopindolol-TS$\beta_{1} \mathrm{AR}_{\mathrm{A} 227 \mathrm{Y} / \mathrm{L} 343 \mathrm{Y}}$ complex (Extended Data Figure 7A), indicating that cyanopindolol replaces isoprenaline and causes the release of NB80. In agreement with the G protein activation data, the isoprenaline-bound original TS- $\beta_{1} \mathrm{AR}$ and the mutants TS- $\beta_{1} \mathrm{AR}_{\mathrm{A} 227 \mathrm{Y}}$ and TS- $\beta_{1} \mathrm{AR}_{\mathrm{L} 343 \mathrm{Y}}$ did not show binding of NB80 in the NMR spectra. Moreover, supplementing NB80 to the ultrastable TS- $\beta_{1}$ AR did not change its affinity for isoprenaline (Extended Data Figure 7B), whereas it caused a hundred-fold affinity increase for $\mathrm{TS}-\beta_{1} \mathrm{AR}_{\mathrm{A} 227 \mathrm{Y} / \mathrm{L} 343 \mathrm{Y}}$ and the truncated 
native turkey $\beta_{1} \mathrm{AR}$ receptor $(\mathrm{t} \beta \text { trunc })^{17}$. This increase is identical to data for $\beta_{2} \mathrm{AR}^{18}$ and shows the energetic coupling between the NB80 and agonist binding also for $\beta_{1} \mathrm{AR}$.

In combination, these data prove that agonist binding, even in the absence of a $\mathrm{G}$ proteinmimic, induces or stabilizes initial changes in the conformational equilibrium of TM5 towards the conformation observed in the $G$ protein complex of $\beta_{2} A R$. Remarkably, these rearrangements occur in all thermostabilized forms of $\beta_{1} \mathrm{AR}$. However, a full shift of the equilibrium towards such an active conformation including allosteric changes at the extracellular side occurs only when $G$ protein or its mimetic NB80 is bound. This process requires the presence of both Y227(5.58) and Y343(7.53), which significantly reduce the thermal stability. Different active conformations may be reached for non-G protein effectors such as $\beta$-arrestin.

The possibility to detect NMR signals at many receptor sites in response to ligand binding and point mutations provides an experimental method to trace allosteric signaling paths. Figure 3 shows examples of these pathways, derived from the response to the ligands atenolol and isoprenaline and the single point mutations V129(3.40)I, A227(5.58)Y, and L343(7.53)Y. Choosing a cutoff of $0.05 \mathrm{ppm}$ for the resulting combined ${ }^{1} \mathrm{H},{ }^{15} \mathrm{~N}$ chemical shift change (Figure 3A, red line), long-range ( $>10 \AA$ ) connections become evident throughout the receptor (Figure 3B and C). Whereas detected ligand signals radiate broadly to almost all helices, the point mutants give evidence of smaller interaction networks connecting TM3 to TM4/5, TM5 to TM3/4/6, as well as TM7 to TM2/3 (Figure 3B,C). Interestingly, the TM2/TM7 network appears to be only weakly connected to the TM3-6 network. Together, these data provide experimental evidence at high resolution of an extensive signal transduction network that connects the ligand binding site to the intracellular sides of TM5, TM6, and TM7. Such a network of loosely coupled allosteric connections has been postulated previously for $\beta_{2} \mathrm{AR}$ based on molecular dynamics simulations ${ }^{24}$.

In summary, we have shown that highly resolved solution NMR backbone spectra can be obtained for a eukaryotic GPCR. The NMR observations delineate the allosteric signaling pathways and comprehensively connect many previous experimental and theoretical observations, which may ultimately allow to understand the dynamic mechanisms of GPCRs at the atomic level. 


\section{Acknowledgments}

We gratefully acknowledge Dr. Timothy Sharpe of the Biozentrum Biophysics Facility for expert help with biophysical assays. We thank Prof. Jan Steyaert (Vrije Universiteit Brussel) for providing the NB80 plasmid and Marco Rogowski for preparing wild-type $\beta_{1} A R$ baculovirus. FB was supported by Marie Curie and EMBO postdoctoral fellowships. This work was supported by Swiss National Science Foundation grants 31-132857 (S.G.), Sinergia 141898 (SG, DBV, GFXS), 31-135754 (DBV), 31-153145 (GFXS), 31-146520 (XD), and COST Action CM1207 (GLISTEN) (XD and GFXS).

\section{Author Contributions}

S.G., G.F.X.S., D.B.V., X.D. and S.I. initiated and managed the project. S.I., X.D., F.B., D.B.V., G.F.X.S. and S.G. designed ligand response and selective labeling experiments. C.O. designed initial TS- $b_{1}$ AR construct and established purification. S.I. designed and prepared all selectively labeled receptor mutants, performed ligand exchange, NB80 binding, and all NMR experiments. S.I. and S.G. designed NMR experiments, analyzed and interpreted all data. F.M.H. and D.B.V . purified trimeric $\mathrm{G}_{\mathrm{i}}$ protein, designed and performed radioligand affinity and $\mathrm{G}_{\mathrm{i}}$ protein activation assays. C.J.T. prepared NB80 nanobody. S.G., S.I., X.D., F.M.H., D.B.V. and G.F.X.S. wrote the manuscript.

\section{Author Information}

The authors declare no competing financial interests. 


\section{Methods}

\section{$\beta_{1} A R$ constructs}

The TS- $\beta_{1}$ AR mutant was derived from the turkey $\beta_{1}$ AR44-m23 mutant used in crystallographic studies $^{25}$ by adding three additional thermostabilizing mutations (I129V, D322K, and Y343L) and a neutral mutation (D200E) from the ultra-stable $\beta_{1}$ AR-JM3 mutant ${ }^{11}$. As compared to the wild type, TS- $\beta_{1} \mathrm{AR}$ contains truncations at the $\mathrm{N}$ - and C-termini and intracellular loop (ICL3), a total of nine thermostabilizing point mutations, three further point mutations as well as a C-terminal hexahistidine tag (Extended Data Figure 1). The final TS- $\beta_{1}$ AR sequence is

\section{MGAELLSQQWEAGMSLLMAL VVLLIVAGNVLVIAAIGSTQ RLQTLTNLFITSLACADLVV GLLVVPFGATLVVRGTWLWG SFLCELWTSLDVLCVTASVE TLCVIAIDRYLAITSPFRYQ SLMTRARAKVIICTVWAISA LVSFLPIMMHWWRDEDPQAL KCYQDPGCCEFVTNRAYAIA SSIISFYIPLLIMIFVALRV YREAKEQIRKIDRASKRKTS RVMLMREHKALKTLGIIMGV FTLCWLPFFLVNIVNVFNRD LVPKWLFVAFNWLGYANSAM NPIILCRSPDFRKAFKRLLA FPRKADRRLHHHHHH .}

Additional valine-to-alanine or isoleucine point mutations were introduced into TS- $\beta_{1} \mathrm{AR}$ for NMR assignment purposes. All constructs were made using the QuikChange site-directed mutagenesis method (Agilent). Baculovirus for insect cell expression was generated using the Bac-to-Bac system (Invitrogen).

\section{$\beta_{1} A R$ expression and purification}

All $\beta_{1}$ AR constructs were expressed in baculovirus-infected insect cells as described ${ }^{26}$. Selective labeling by ${ }^{15} \mathrm{~N}$-valine was achieved by growing cells on unlabeled serum-free insect cell medium (InsectXpress, Lonza) and then exchanging into custom-made serum-free medium (SF4, BioConcept) devoid of valine and yeast extract, to which $100 \mathrm{mg} / \mathrm{L}{ }^{15} \mathrm{~N}$-valine were supplemented. Virus was added immediately after the medium exchange. The culture was harvested at 48 or $72 \mathrm{hr}$ post infection.

After cell lysis, the membrane fraction was separated from the lysate via ultracentrifugation and subsequently solubilized with $2 \% n$-decyl- $\beta$-D-maltopyranoside (DM, Anatrace). The solubilized membrane fraction was then purified by nickel ion affinity chromatography followed by alprenolol ligand affinity chromatography. The active receptor was eluted with buffer (20 mM TRIS, $350 \mathrm{mM} \mathrm{NaCl}, 0.1 \% \mathrm{DM}, \mathrm{pH}$ 7.5) containing either atenolol $(1 \mathrm{mM})$ or alprenolol $(0.1 \mathrm{mM})$. Final yields of detergent-solubilized receptor were 
$1.5 \mathrm{mg} / \mathrm{L}$ of cell culture. The molecular weight of the receptor-detergent complex was estimated as $\sim 100 \mathrm{kDa}$ by static light scattering.

\section{Thermal shift assays of mutant receptors}

Detergent-solubilized, purified apo TS- $\beta_{1}$ AR and reverse-mutation receptors for thermal stability assays were obtained from their atenolol-bound form by washing with buffer devoid of ligand on a HiTrap SP HP (GE Healthcare) column. Their thermal stability was determined by the microscale fluorescent stability assay for binding of the thiol-specific fluorochrome N[4-(7-diethylamino-4-methyl-3-coumarinyl)phenyl]maleimide $(\mathrm{CPM})^{27}$ in a Rotor-Gene Q (QIAGEN) real-time PCR cycler using $1 \mu \mathrm{g}$ of receptor in $20 \mathrm{mM}$ TRIS, $350 \mathrm{mM} \mathrm{NaCl}, 0.1 \%$ $\mathrm{DM}, \mathrm{pH} 7.5$ and a heating rate of $2 \mathrm{~K} / \mathrm{min}$.

\section{NMR experiments}

NMR samples were prepared in Shigemi tubes as $250 \mu$ l volumes of typically $100 \mu \mathrm{M}$ receptor, $1 \mathrm{mM}$ ligand (except for apo form), $20 \mathrm{mM}$ TRIS, $100 \mathrm{mM} \mathrm{NaCl}, 0.1 \% \mathrm{DM}, 5 \%$ $\mathrm{D}_{2} \mathrm{O}, \mathrm{pH}$ 7.5. For isoprenaline or dobutamine, $2 \mathrm{mM}$ of sodium L-ascorbate were supplemented as anti-oxidant. All solution NMR measurements were carried out on a $800 \mathrm{MHz}$ or a $900 \mathrm{MHz}$ Bruker Avance III spectrometer equipped with a cryogenic probe at $304 \mathrm{~K}$. 2D ${ }^{1} \mathrm{H},{ }^{15} \mathrm{~N}$ TROSY (transverse relaxation-optimized spectroscopy) spectra were recorded with total acquisition periods of $16 \mathrm{~ms}\left({ }^{15} \mathrm{~N}\right)$ and $43 \mathrm{~ms}\left({ }^{1} \mathrm{H}\right)$ with typical total experimental times of 24-48 h. As compared to a standard TROSY pulse sequence, the ${ }^{1} \mathrm{H}^{-15} \mathrm{~N}$ INEPT delays were set to $3 \mathrm{~ms}$ to reduce magnetization losses from relaxation.

\section{Assignment procedure}

To obtain sequence-specific assignment information, we initially attempted to detect $\mathrm{HNCO}$ and HNCA correlations on samples additionally labeled with ${ }^{13} \mathrm{C}$ at specific backbone $\operatorname{sites}^{28}$. However, due to low sensitivity, only very few correlations were observable. Therefore, assignments were obtained from a combination of information from TROSY spectra recorded on $18 \mathrm{TS}-\beta_{1} \mathrm{AR}$ valine point mutants with different ligands, four $\mathrm{HN}(\mathrm{CO})$ correlations and five distinct structure-based chemical shift predictions (Extended Data Table 2).

\section{Ligand exchange experiments}

Receptor complexes with different ligands were generated by sequential exchange according to increasing ligand affinity, i.e. in the sequence atenolol-isoprenaline-dobutaminealprenolol or alprenolol-carvedilol-cyanopindolol. For exchange, the sample was washed three times with buffer devoid of ligand at 10-fold dilution in Amicon Ultra $50 \mathrm{kDa}$ cutoff 
concentrators. Subsequently, the sample was washed again twice with buffer containing $100 \mu \mathrm{M}$ new ligand, separated by a period of $1 \mathrm{~h}$ incubation. Final concentrations of the ligands were adjusted to $1 \mathrm{mM}$. Apo receptor was generated from the atenolol complex by six washing steps of 10-fold dilution in ligand-free buffer using a $1 \mathrm{~h}$ incubation period for the last three steps.

\section{NMR NB80 binding experiment}

Binding of NB80 to $\beta_{1} \mathrm{AR}$ mutants was assessed using TROSY and 1D proton NMR spectra. These spectra were recorded on the $\beta_{1} \mathrm{AR}$ mutants $\left(\mathrm{TS}-\beta_{1} \mathrm{AR}: 132 \mu \mathrm{M}, \mathrm{TS}-\beta_{1} \mathrm{AR}_{\mathrm{A} 227 \mathrm{Y}}\right.$ : $120 \mu \mathrm{M}$, TS- $\beta_{1} \mathrm{AR}_{\mathrm{L} 343 \mathrm{Y}}: 110 \mu \mathrm{M}$, and TS- $\left.\beta_{1} \mathrm{AR}_{\mathrm{A} 227 \mathrm{Y} / \mathrm{L} 343 \mathrm{Y}}: 120 \mu \mathrm{M}\right)$ in the presence of saturating amounts $(1 \mathrm{mM})$ of the agonist isoprenaline before and immediately after addition of an equimolar (relative to the receptor) amount of NB80. For TS- $\beta_{1} \mathrm{AR}_{\mathrm{A} 227 \mathrm{Y} / \mathrm{L} 343 \mathrm{Y}}$ additional spectra were recorded after a further addition of the partial agonist cyanopindolol $(1 \mathrm{mM})$ to the already present isoprenaline and NB80.

\section{Scintillation proximity assay with ${ }^{3} \mathrm{H}$-dihydroalprenolol}

For pharmacological binding assays membranes were prepared from SF9 insect cells as described previously ${ }^{26}$. The total protein content of the membranes was estimated by A280 measurements using an average extinction coefficient of 1.0 per $\mathrm{mg} / \mathrm{ml}$. All assays were carried out in 96-well plates at $200 \mu \mathrm{g} / \mathrm{ml}$ total protein in membranes and $2 \mathrm{mg} / \mathrm{ml} \mathrm{WGA-YSi}$ beads (Perkin-Elmer) in a $100 \mu \mathrm{l}$ total volume per well. Samples were equilibrated at room temperature for at least 16 h. $K_{\mathrm{D}}$ values for the radioactive ligand ${ }^{3} \mathrm{H}$-dihydroalprenolol $\left({ }^{3} \mathrm{H}\right.$ DHA) were determined by titrating ${ }^{3} \mathrm{H}$-DHA from 0.032 to $100 \mathrm{nM}$. Non-specific binding was determined in presence of $1 \mu \mathrm{M}$ S-propanolol to block the ligand binding site. Competition assays were performed in the presence of $20 \mathrm{nM}{ }^{3} \mathrm{H}$-DHA (hot ligand) and increasing concentrations of the competitor (cold ligand). Dilutions of alprenolol, atenolol, cyanopindolol, dobutamine and isoprenaline were made with phosphate buffered saline (PBS, Biochrom, Germany). Due to the limited solubility of carvedilol in water, stock dilutions of carvedilol were prepared in DMSO. The final concentration of DMSO in the samples was $5 \%$. To test the effect of NB80 binding on the affinities $\left(I C_{50}\right)$ of isoprenaline for various receptor mutants, the competition assays were also carried out in the presence of saturating concentrations of NB80 $(10 \mu \mathrm{M}) . I C_{50}$ values were determined by fitting the measured radioactive counts per minute $C P M(X)$ at a specific concentration $X$ of the competitor to the equation $C P M(X)=\frac{C P M_{\max }-C P M_{\min }}{1+\frac{X}{I C_{50}}}+C P M_{\text {min }}$, where $C P M_{\text {max }}$ and $C P M_{\text {min }}$ are maximal and minimal counts of the assay, respectively. The fits were carried in MATLAB 
(MathWorks, www.mathworks.com) with Monte-Carlo estimation of errors. $K_{i}$ values were calculated from the obtained $I C_{50}$ values according to the formula $K_{i}=\frac{I C_{50}}{1+\frac{A}{K_{D}}}$ where $A$ is the concentration of the radioactive ligand and $K_{\mathrm{d}}$ is its affinity for the receptor determined in the direct binding experiment.

\section{G protein activation assay}

$\mathrm{G}$ protein activation was measured on purified $\beta_{1} \mathrm{AR}$ mutants reconstituted with MSP1E3D1 ${ }^{29}$ into POPC/POPG nanodiscs. MSP1E3D1 was expressed and purified as described $^{29}$ and cleaved with TEV protease. 1-palmitoyl-2-oleoyl-sn-glycero-3phosphocholine (POPC, Avanti Polar Lipids) and 1-palmitoyl-2-oleoyl-sn-glycerol-3phospho-(1'-rac-glycerol) sodium salt (POPG, Avanti Polar Lipids) were solubilized at a ratio of 1:1.5 (w/w) POPG/POPC in ND buffer (20 mM HEPES pH 8, $100 \mathrm{mM} \mathrm{NaCl}, 1 \mathrm{mM}$ EDTA) with $50 \mathrm{mM}$ sodium cholate (Sigma-Aldrich) at $4{ }^{\circ} \mathrm{C}$. 133.3 $\mu \mathrm{M}$ MSP1E3D1 was incubated with $8 \mathrm{mM}$ solubilized POPC/POPG and $10 \mu \mathrm{M}$ purified $\beta_{1} \mathrm{AR}$ in ND buffer with a final concentration of $24 \mathrm{mM}$ sodium cholate for $1 \mathrm{~h}$ at $4{ }^{\circ} \mathrm{C}$. Nanodiscs containing the receptor were separated from empty nanodiscs using a cobalt-chelating resin. The heterotrimeric $\mathrm{G}$ protein was prepared by incubating $10 \mu \mathrm{M}$ recombinant Gail and $10 \mu \mathrm{M}$ native $\mathrm{G} \beta \gamma \mathrm{t}$ in activation buffer (25 mM HEPES pH 7.5, $150 \mathrm{mM} \mathrm{NaCl}, 2 \mathrm{mM} \mathrm{MgCl}, 1 \mathrm{mM}$ DTT) for $30 \mathrm{~min}$ at $4{ }^{\circ} \mathrm{C}$.

G protein activation was detected by the change in tryptophan fluorescence caused by the exchange of GDP for GTP $\gamma \mathrm{S}$, associated conformational changes in the G $\alpha$ subunit and its dissociation from the $G \beta \gamma$ subunit of the heterotrimeric $G$ protein ${ }^{30}$. All measurements were carried out on a Varian Cary Eclipse fluorescence spectrophotometer $\left(\lambda_{\mathrm{ex}}=295 \mathrm{~nm}, \lambda_{\mathrm{em}}=340\right.$ $\mathrm{nm}, 1.5 \mathrm{~nm}$ excitation slit, $20 \mathrm{~nm}$ emission slit, $2 \mathrm{~s}$ averaging time, $15 \mathrm{~s}$ cycle time) using final sample volumes of $1 \mathrm{ml}$ in $10 \times 4 \mathrm{~mm}$ cuvettes (Hellma, $\mathrm{CH}$ ) and magnetic stirrers at $20^{\circ} \mathrm{C}$. Prior to activation, the fluorescence intensity baseline was recorded with $100 \mathrm{nM}$ heterotrimeric $\mathrm{G}$ protein for approximately $500 \mathrm{~s}$. The activation was started by adding $6 \mathrm{nM}$ $\beta_{1} \mathrm{AR}$ and $10 \mu \mathrm{M}$ GTP $\gamma \mathrm{S}$, and the fluorescence intensity was monitored for a further $1 \mathrm{~h}$. For experiments in the presence of an agonist, the concentrated receptor stock solution $(1.5 \mu \mathrm{M})$ was pre-incubated for $30 \mathrm{~min}$ at $4{ }^{\circ} \mathrm{C}$ with $40 \mu \mathrm{M}$ isoprenaline, and the buffer during the measurements contained $2 \mu \mathrm{M}$ of isoprenaline to maintain the saturation conditions for the receptor. 


\section{Figure legends}

Figure 1: Ligand-induced ${ }^{1} \mathrm{H}-{ }^{15} \mathrm{~N}$ chemical shift changes in the vicinity of the ligand binding pocket of $\beta_{1} \mathrm{AR}$.

(a) Partial view of the $\beta_{1}$ AR-carvedilol crystal structure (4AMJ) showing valine residues (blue spheres) in the vicinity $(<8.5 \AA$ ) of the ligand (magenta sticks) binding site.

(b) Chemical structures of the $\beta_{1} A R$ ligands used in this study. Ligand affinities derived from whole cell binding assays on the thermostabilized $\beta 36-\mathrm{m} 23 \beta_{1} \mathrm{AR}$ construct $^{17}$ are indicated as $\mathrm{p} K_{D}$ values. Similar $\mathrm{p} K$ values were measured for the TS- $\beta_{1} \mathrm{AR}$ construct (Extended Data Table 1).

(c, left) Ligand-induced response of V172(4.56) ${ }^{1} \mathrm{H}-{ }^{15} \mathrm{~N}$ resonances. The black bar represents a scale of $0.1 \mathrm{ppm}\left({ }^{1} \mathrm{H}\right)$ and $1 \mathrm{ppm}\left({ }^{15} \mathrm{~N}\right)$. The labels $o, m, p$ indicate respectively ligands with ortho, meta, and para substitutions at the head group.

(c, right) Partial view of the $\beta_{1}$ AR-carvedilol structure (4AMJ) showing the interaction network connecting V172(4.56) to S215(5.461), P219(5.50), I129(3.40), and F299(6.44).

(d, left) Representation as (c, left) for the ${ }^{1} \mathrm{H}-{ }^{15} \mathrm{~N}$ resonances of V314(6.59). Centers of resonances are indicated by circles.

(d, middle) Correlation of a best-fit linear combination of the V314(6.59) chemical shifts $\left(48.9 \delta^{1} \mathrm{H}+0.986 \delta^{15} \mathrm{~N}-488\right)$ to the ligand affinity $\mathrm{p} K_{D}$ (Extended Data Table 1$)$.

(d, right) Partial view of the carvedilol (red, 4AMJ), dobutamine (orange, 2Y01), cyanopindolol (green, 2VT4 B), and isoprenaline (blue, 2Y03) complex structures showing the ligand-induced movement of V314(6.59).

(e, left) Representation as (d, left) for the ${ }^{1} \mathrm{H}^{-15} \mathrm{~N}$ resonances of $\mathrm{V} 125(3.36)$ and $\mathrm{V} 103(2.65)$.

(e, middle) Correlations of best-fit linear combinations of chemical shifts for V125(3.36) $\left(-0.402 \delta^{1} \mathrm{H}+1.17 \delta^{15} \mathrm{~N}-132\right)$ and $\mathrm{V} 103(2.65)\left(-336 \delta^{1} \mathrm{H}-634 \delta^{15} \mathrm{~N}+7.64 \cdot 10^{4}\right)$ to the ligand insertion depths and tail volumes (Extended Data Table 1), respectively.

(e, right) Partial view of the carvedilol, dobutamine, cyanopindolol, and isoprenaline crystal structures (representation as $\mathbf{d}$, right) showing the ligand-induced movement of V125(3.36), D121(3.32), and V103(2.65).

Figure 2: Correlation of ligand-induced chemical shift changes at the TS- $\beta_{1} A R$ intracellular side with Gs efficacy.

(a, top) Response of the V226(5.57) ${ }^{1} \mathrm{H}^{-15} \mathrm{~N}$ resonance to various ligands (color coding as in Figure 1). The centers of resonances are indicated by circles. The ${ }^{1} \mathrm{H}_{-}{ }^{15} \mathrm{~N}$ resonances fall on one line from atenolol (antagonist) over apo to alprenolol (partial agonist), carvedilol (antagonist), cyanopindolol (partial agonist), dobutamine (full agonist) and isoprenaline (full agonist).

(a, bottom) Correlation of a best-fit linear combination of the V226(5.57) chemical shifts $\left(-515 \delta^{1} \mathrm{H}-31.7 \delta^{15} \mathrm{~N}+8.41 \cdot 10^{3}\right)$ in different ligand complexes to their efficacy for the Gs signaling pathway ${ }^{17}$.

(b, top) Overlay of TM5 and TM6 backbones of thermostabilized $\beta_{1} \mathrm{AR}$ in antagonist- (blue, PDB code 4AMJ) and agonist-bound (green, PDB code 2Y03) form. The agonist does not induce detectable helix movements.

(b, bottom) TM5 and TM6 backbone movements upon activation in human $\beta_{2} \mathrm{AR}$. The overlay of inactive (blue, PDB code 2RH1) and G protein-bound $\beta_{2} \mathrm{AR}$ (magenta, PDB code 3SN6) 
structures shows the large bend of TM6 along with the smaller conformational change of TM5 upon activation. Hydrogen bonds $5.57-\mathrm{H}^{\mathrm{N}} \cdots 5.53-\mathrm{O}$ and $5.61-\mathrm{H}^{\mathrm{N}} \cdots 5.57-\mathrm{O}$ are indicated by dashes. According to the behavior of the ${ }^{1} \mathrm{H}^{\mathrm{N}}$ chemical shifts of V226(5.57) and V230(5.61) in TS- $\beta_{1} A R$, these hydrogen bonds expand in an efficacy-dependent manner during agonist binding.

(c) Response of the ${ }^{1} \mathrm{H}-{ }^{15} \mathrm{~N}$ resonances for V226(5.57), V230(5.61), V298(6.43), and V280(6.25) to various ligands. For clarity, only the centers of resonances are depicted as circles with color coding as in Figure 1. The black bar represents a scale of $0.1 \mathrm{ppm}$ and $1 \mathrm{ppm}$ for the ${ }^{1} \mathrm{H}$ and ${ }^{15} \mathrm{~N}$ chemical shifts, respectively. The schematic representation of the receptor indicates the locations of the respective valine residues at the cytoplasmic sides of TM5 and TM6 within the helical bundle of $\beta_{1} \mathrm{AR}$.

Figure 3: Experimental detection of allosteric signaling pathways using the NMR response to ligand binding and point mutations at different backbone sites.

(a) Combined ${ }^{1} \mathrm{H},{ }^{15} \mathrm{~N}$ chemical shift deviations $\left[\Delta \delta=\left(\Delta \delta_{1 \mathrm{H}}{ }^{2} / 2+\Delta \delta_{15 \mathrm{~N}}{ }^{2} / 50\right)^{1 / 2}\right]$ of valine resonances observed upon ligand binding or induced by the indicated point mutations. For ligand binding, the three pairwise deviations $\Delta \delta$ were calculated between the apo, atenolol-, and isoprenaline-bound forms of TS- $\beta_{1} \mathrm{AR}$. The maximum of these deviations is shown. For the reverse mutants, deviations $\Delta \delta$ are shown relative to TS- $\beta_{1} \mathrm{AR}$ for their apo (black), atenolol- (cyan), and isoprenaline-bound (blue) bound forms. Valines within $10 \AA$ from the $\mathrm{C}^{\alpha}$ atom of the mutated amino acid are shown on a grey background. Distances were calculated using the coordinates of the thermostabilized $\beta_{1} \mathrm{AR}$ (PDB code $4 \mathrm{BVN}$ ). A red line marks a cutoff value $\Delta \delta$ of $0.05 \mathrm{ppm}$ for significant chemical shift deviations.

(b) Topology of the signaling network determined from point mutations (left) and ligand binding (right). Signal paths were identified by chemical shift deviations $\Delta \delta$ larger than 0.05 ppm induced by these two perturbations (panel a). Signal paths to valines within $10 \AA$ from the ligand or point mutation (i.e. localized conformational changes) are indicated as dashed lines, and those beyond $10 \AA$ (long-range conformational changes) as solid lines. The ligand signals broadly towards all helices but TM1. In contrast, the network determined by the point mutations is more localized and connects TM3 to TM4/5, TM5 to TM3/4/6, and TM7 to TM2/3. The latter network appears to be divided into two subnetworks involving TM3/4/5/6 and $\mathrm{TM} 2 / 7$.

(c) Long-range allosteric signal paths identified from ligand binding or point mutations (Figure $3 \mathbf{a}$ and $\mathbf{b}$ ) indicated on schematic $\beta_{1}$ AR representations showing the involved TMs. Helices are color-coded according to panel $\mathbf{b}$. 


\section{References}

1. Rasmussen, S. G. F. et al. Crystal structure of the human beta2 adrenergic G-proteincoupled receptor. Nature 450, 383-387 (2007).

2. Rasmussen, S. G. F. et al. Crystal structure of the $\mathrm{b} 2$ adrenergic receptor-Gs protein complex. Nature 477, 549-555 (2011).

3. Ghosh, E., Kumari, P., Jaiman, D. \& Shukla, A. K. Methodological advances: the unsung heroes of the GPCR structural revolution. Nat Rev Mol Cell Biol 16, 69-81 (2015).

4. Grzesiek, S. \& Sass, H.-J. From biomolecular structure to functional understanding: new NMR developments narrow the gap. Curr. Opin. Struct. Biol. 19, 585-595 (2009).

5. Bokoch, M. P. et al. Ligand-specific regulation of the extracellular surface of a Gprotein-coupled receptor. Nature 463, 108-112 (2010).

6. Kofuku, Y. et al. Efficacy of the $\beta 2$-adrenergic receptor is determined by conformational equilibrium in the transmembrane region. Nat Commun 3, 1045-9 (2012).

7. Liu, J. J., Horst, R., Katritch, V., Stevens, R. C. \& Wuthrich, K. Biased Signaling Pathways in 32 -Adrenergic Receptor Characterized by 19F-NMR. Science 335, 11061110 (2012).

8. Nygaard, R. et al. The dynamic process of $\beta(2)$-adrenergic receptor activation. Cell 152, 532-542 (2013).

9. Manglik, A. et al. Structural Insights into the Dynamic Process of $\beta 2$-Adrenergic Receptor Signaling. Cell 161, 1101-1111 (2015).

10. Warne, T. et al. Structure of a beta1-adrenergic G-protein-coupled receptor. Nature 454, 486-491 (2008).

11. Miller, J. L. \& Tate, C. G. Engineering an ultra-thermostable $\beta(1)$-adrenoceptor. J. Mol. Biol. 413, 628-638 (2011).

12. Miller-Gallacher, J. L. et al. The 2.1 A Resolution Structure of Cyanopindolol-Bound $\beta 1$-Adrenoceptor Identifies an Intramembrane $\mathrm{Na}+$ Ion that Stabilises the Ligand-Free Receptor. PLoS ONE 9, e92727 (2014).

13. Ballesteros, J. A. \& Weinstein, H. Integrated methods for the construction of threedimensional models and computational probing of structure-function relations in $\mathrm{G}$ protein-coupled receptors. Methods in Neurosciences 25, 366-428 (1995).

14. Deupi, X. \& Standfuss, J. Structural insights into agonist-induced activation of Gprotein-coupled receptors. Curr. Opin. Struct. Biol. 21, 541-551 (2011).

15. Dror, R. O. et al. Pathway and mechanism of drug binding to G-protein-coupled receptors. Proc. Natl. Acad. Sci. USA 108, 13118-13123 (2011).

16. Gonzalez, A., Perez-Acle, T., Pardo, L. \& Deupi, X. Molecular basis of ligand dissociation in $\beta$-adrenergic receptors. PLoS ONE 6, e23815 (2011).

17. Baker, J. G., Proudman, R. G. W. \& Tate, C. G. The pharmacological effects of the thermostabilising $(\mathrm{m} 23)$ mutations and intra and extracellular $(\beta 36)$ deletions essential for crystallisation of the turkey $\beta$-adrenoceptor. Naunyn Schmiedebergs Arch. Pharmacol. 384, 71-91 (2011).

18. Rasmussen, S. G. F. et al. Structure of a nanobody-stabilized active state of the $\beta(2)$ adrenoceptor. Nature 469, 175-180 (2011).

19. Manglik, A. \& Kobilka, B. The role of protein dynamics in GPCR function: insights from the $\beta 2 A R$ and rhodopsin. Curr. Opin. Cell Biol. 27, 136-143 (2014).

20. Grzesiek, S., Cordier, F., Jaravine, V. \& Barfield, M. Insights into biomolecular hydrogen bonds from hydrogen bond scalar couplings. Prog Nucl Mag Res Sp 45, 275300 (2004).

21. Tate, C. G. \& Schertler, G. F. Engineering G protein-coupled receptors to facilitate their structure determination. Curr. Opin. Struct. Biol. 19, 386-395 (2009). 
22. Goncalves, J. A. et al. Highly conserved tyrosine stabilizes the active state of rhodopsin. Proc. Natl. Acad. Sci. USA 107, 19861-19866 (2010).

23. Park, J. H., Scheerer, P., Hofmann, K. P., Choe, H.-W. \& Ernst, O. P. Crystal structure of the ligand-free G-protein-coupled receptor opsin. Nature 454, 183-187 (2008).

24. Dror, R. O. et al. Activation mechanism of the $\beta 2$-adrenergic receptor. Proc. Natl. Acad. Sci. USA 108, 18684-18689 (2011).

25. Warne, T. et al. The structural basis for agonist and partial agonist action on a $\beta 1$ adrenergic receptor. Nature 469, 241-244 (2011).

26. Brueckner, F. et al. Structure of $\beta$-adrenergic receptors. Meth Enzymol 520, 117-151 (2013).

27. Alexandrov, A. I., Mileni, M., Chien, E. Y. T., Hanson, M. A. \& Stevens, R. C. Microscale fluorescent thermal stability assay for membrane proteins. Structure 16, 351-359 (2008).

28. Vajpai, N. et al. Backbone NMR resonance assignment of the Abelson kinase domain in complex with imatinib. Biomol NMR Assign 2, 41-42 (2008).

29. Bayburt, T. H., Grinkova, Y. V. \& Sligar, S. G. Self-Assembly of Discoidal Phospholipid Bilayer Nanoparticles with Membrane Scaffold Proteins. Nano Lett. 2, 853-856 (2002).

30. Ernst, O. P., Bieri, C., Vogel, H. \& Hofmann, K. P. Intrinsic biophysical monitors of transducin activation: fluorescence, UV-visible spectroscopy, light scattering, and evanescent field techniques. Meth Enzymol 315, 471-489 (2000).

31. Han, B., Liu, Y., Ginzinger, S. W. \& Wishart, D. S. SHIFTX2: significantly improved protein chemical shift prediction. J. Biomol. NMR 50, 43-57 (2011). 


\section{Extended Data figure and table legends}

Extended Data Figure 1: Position of valine residues in the thermostabilized mutant TS$\beta_{1} \mathrm{AR}$.

(a) Schematic representation of secondary structure and amino acid sequence of TS- $\beta_{1} \mathrm{AR}$. As compared to the wild type, the TS- $\beta_{1} \mathrm{AR}$ has truncations at the $\mathrm{N}$ - and C-termini and the intracellular loop (ICL3) as well as nine thermostabilizing point mutations (color coded green) and three additional point mutations (color coded yellow). Valines labeled with ${ }^{15} \mathrm{~N}$ are indicated by bold circles for assigned (blue) and unassigned (grey) residues.

(b) Structure of $\beta_{1} \mathrm{AR}$ in complex with carvedilol (PDB code 4AMJ). The protein backbone and carvedilol are shown in ribbon and red stick representation, respectively. The individual valines are depicted as spheres (blue: assigned, grey: not assigned) labeled by residue number.

(c) Full ${ }^{1} \mathrm{H}-{ }^{15} \mathrm{~N}$ TROSY spectra of apo TS- $\beta_{1} \mathrm{AR}$ and all investigated ligand complexes. The ligand chemical structures are shown as inserts. Resonances are marked with assignment information (black: firm, cyan: tentative).

Extended Data Figure 2: Effect of ligand head group substitution on hydrogen bond network involving V172(4.56) in $\beta_{1} \mathrm{AR}$.

(a) Sequence alignment of turkey $\beta_{1} \mathrm{AR}$ and human adrenoreceptors around position 4.56 in TM4 showing the conserved proline at position 4.60 .

(b) Schematic representation of the hydrogen bond network between TM4 and TM5 involving $\mathrm{V} 172(4.56)$ in $\beta_{1} \mathrm{AR}$. The hydrogen bond network (orange dotted lines) originates at the carbonyl of V172(4.56) and connects to TM5 via two water molecules (w1 and w2, red asterisks).

(c, left) Phi and psi dihedral angles (averages and standard deviations in case of multiple chains) in TM4 between residues 4.48 and 4.61 for different complexes of $\beta_{1} \mathrm{AR}$ (ligand, PDB code [chain]: carvedilol, 4AMJ [A,B]; cyanopindolol, 2VT4 [B,D] and 4BVN [A]; dobutamine, 2Y00 [A,B] and 2Y01 [A,B]; isoprenaline, 2Y03 [A,B]). V165(4.49) and V172(4.56), for which ${ }^{1} \mathrm{H}-{ }^{15} \mathrm{~N}$ resonances could be observed, are shown on a green and red background, respectively.

(c, right) Average of the ${ }^{1} \mathrm{H}_{-}{ }^{15} \mathrm{~N}$ resonance positions for $\mathrm{V} 165(4.49$, green) and $\mathrm{V} 172(4.56$, red). The phi and psi values of V172(4.56) are distorted from the normal helical angles due to the loss of the intra-helical hydrogen bond to P176(4.60). Together with the loss of the canonical hydrogen bond, this strongly shifts both the ${ }^{1} \mathrm{H}$ and ${ }^{15} \mathrm{~N}$ chemical shifts of V172(4.56) towards smaller ppm values relative to V165(4.49), which has normal, helical phi and psi angles.

(d) Partial views of the crystal structures of the carvedilol complex (PDB code 4AMJ), the isoprenaline complex (PDB code: 2Y03) and a docking model of the atenolol complex based on the cyanopindolol complex crystal structure (PDB code 4BVN). In the carvedilol complex, one water molecule (w2) forms a hydrogen bond network between the carbonyl oxygen of V172(4.56) and the side chains of S211(5.43) and S215(5.461). In the isoprenaline complex, the side chains of S211(5.43) and S215(5.461) are rotated and form hydrogen bonds to the catechol hydroxyl groups of isoprenaline. In this structure, no water molecule is observed at the equivalent position of w2. In the atenolol complex, the para-substituted acetamide of the ligand head ring (dashed circle) inserts between S211(5.43) and S215(5.461) and disturbs the 
interface between TM3 and TM5 near V172(4.56) (solid circle).

Extended Data Figure 3: Response to various ligands for all assigned valine ${ }^{1} \mathrm{H}-{ }^{15} \mathrm{~N}$ resonances in TS- $\beta_{1} \mathrm{AR}$. Color coding as in Extended Data Figure 1: cyan (atenolol), blue (isoprenaline), orange (dobutamine), purple (alprenolol), red (carvedilol), green (cyanopindolol), black (apo receptor). For clarity the centers of resonances are marked by circles. Firmly (tentatively) assigned residues are marked in black (cyan).

Extended Data Figure 4: Evidence for micro- to millisecond dynamics at the ligand entry/exit pathway. (Left) Region of the ${ }^{1} \mathrm{H}-{ }^{15} \mathrm{~N}$ TROSYs showing the V314(6.59) ${ }^{1} \mathrm{H}-{ }^{15} \mathrm{~N}$ resonance of TS- $\beta_{1} \mathrm{AR}$ in the apo and various ligand-bound forms. The resonances of the apo and atenolol-bound forms are severely broadened in the ${ }^{15} \mathrm{~N}$ dimension indicative of backbone dynamics in the micro- to millisecond range. The broadening is not observed for the other more tightly binding ligands. The resonances for the low affinity ligands, atenolol, isoprenaline and dobutamine, and for the high affinity ligands, alprenolol, carvedilol and cyanopindolol cluster at different positions. Interestingly, the resonance of the apo form clusters with the high affinity ligands, indicative of a similar backbone conformation.

(Right) ${ }^{15} \mathrm{~N}$ and ${ }^{1} \mathrm{H}$ line widths of the V314(6.59) resonance for the apo and ligand-bound forms of TS- $\beta_{1} \mathrm{AR}$.

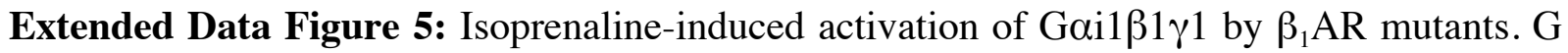
protein activation was measured by the change in tryptophan fluorescence upon exchange of GDP for GTP $\gamma S$ in the G $\alpha$ subunit of the heterotrimeric $G$ protein. The figure shows the time courses of tryptophan fluorescence after the addition of different mutant forms of TS- $\beta_{1}$ AR in nanodiscs and GTP $\gamma \mathrm{S}$ to the heterotrimeric G protein in the presence (red) and absence (black) of the agonist isoprenaline. The increase in fluorescence intensity at time $t=0$ is caused by the additional fluorescence of the receptor, the nanodisc scaffold protein and the ligand. For the active mutant TS- $\beta_{1} \mathrm{AR}_{\mathrm{A} 227 \mathrm{Y} / \mathrm{L} 343 \mathrm{Y}}$, this initial rise is followed by an exponential fluorescence increase due to the activation and dissociation of the $\mathrm{G}$ protein.

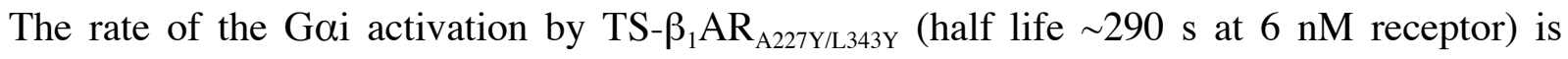
approximately 4 times slower than for the activation by rhodopsin (half life $\sim 400 \mathrm{~s}$ at $1 \mathrm{nM}$ receptor) using the same assay. This assumes that the $K_{\mathrm{m}}$ of Gai for TS- $\beta_{1} \mathrm{AR}_{\mathrm{A} 227 \mathrm{Y} / \mathrm{L} 343 \mathrm{Y}}$ is of the same scale as for rhodopsin $(8.6 \mathrm{nM})$ and therefore significantly below the (saturating) concentration of Gai $(100 \mathrm{nM})$. Each mutant was measured three times except for TS$\beta_{1} \mathrm{AR}_{\mathrm{A} 227 \mathrm{Y} / \mathrm{L} 343 \mathrm{Y}}$ that was measured four times. Representative fluorescence curves from single experiments are shown.

Extended Data Figure 6: Observed NMR effects of the reverse mutations of TS- $\beta_{1} \mathrm{AR}$ towards the native $\beta_{1} \mathrm{AR}$ sequence.

(a) ${ }^{1} \mathrm{H}-{ }^{15} \mathrm{~N}$ TROSY spectra of TS- $\beta_{1} \mathrm{AR}$ and several reverse single and double mutants in complex with either atenolol (cyan) or isoprenaline (dark blue). Resonances are marked with assignment information (black: definite, cyan: tentative).

(b) Enlarged regions of the ${ }^{1} \mathrm{H}-{ }^{15} \mathrm{~N}$ correlation spectra showing only the resonance positions of V226(5.57) and V280(6.25) for all mutants in both ligand-receptor complexes. The black bar 
represents $0.1 \mathrm{ppm}$ in ${ }^{1} \mathrm{H}$ and $1 \mathrm{ppm}$ in ${ }^{15} \mathrm{~N}$. For all mutants, the resonances for V226(5.57) show efficacy-related chemical shift changes between atenolol (diamonds) and isoprenaline (circles). For the $\mathrm{A} 227 \mathrm{Y}$ mutants $\mathrm{TS}-\beta_{1} \mathrm{AR}_{\mathrm{A} 227 \mathrm{Y}}$ (green), TS- $\beta_{1} \mathrm{AR}_{\mathrm{V} 1291 / \mathrm{A} 227 \mathrm{Y}}$ (orange) and TS$\beta_{1} \mathrm{AR}_{\mathrm{A} 227 \mathrm{Y} / \mathrm{L} 343 \mathrm{Y}}$ (cyan), the ${ }^{1} \mathrm{H}-{ }^{15} \mathrm{~N}$ resonances of $\mathrm{V} 226(5.57)$ also exhibit an overall shift due to a ring current effect from the introduced $Y 227(5.58)$ side chain, which has no structural significance. However, the V129I mutants TS- $\beta_{1} \mathrm{AR}_{\mathrm{V} 129 \mathrm{I}}$ (red) and TS- $\beta_{1} \mathrm{AR}_{\mathrm{V} 129 \mathrm{I} / \mathrm{A} 227 \mathrm{Y}}$ (orange) exhibit further ${ }^{1} \mathrm{H}_{-}{ }^{15} \mathrm{~N}$ shifts towards a more active (i.e. bent) state of TM5 relative to the mutants that carry the V129(3.40) residue. For all mutants, the V280(6.25) resonances fall basically in identical positions and show no changes between atenolol and isoprenaline.

Extended Data Figure 7: Binding of NB80 to agonist-activated TS- $\beta_{1} \mathrm{AR}_{\mathrm{A} 227 \mathrm{Y} / \mathrm{L} 343 \mathrm{Y}}$.

(a) Sequential addition of isoprenaline (1 mM, blue), NB80 (120 $\mu \mathrm{M}$, red), and cyanopindolol (1 mM, green) to TS- $\beta_{1} \mathrm{AR}_{\mathrm{A} 227 \mathrm{Y} / \mathrm{L} 343 \mathrm{Y}}(120 \mu \mathrm{M})$ followed by ${ }^{1} \mathrm{H}-{ }^{15} \mathrm{~N}$ TROSY spectra. Addition of an equimolar amount of NB80 changes the spectrum drastically. Except for few resonances $(62,89,102,103,172,280$ and 326), the assignments are not transferable from the isoprenaline complex. The addition of cyanopindolol to this mixture apparently replaces isoprenaline in the receptor and drives the spectrum to the purely cyanopindolol-bound form. These results indicate that TS- $\beta_{1} \mathrm{AR}_{\mathrm{A} 227 \mathrm{Y} / \mathrm{L} 33 \mathrm{Y}}$ can be activated, but that the fully active state requires stabilization with a $\mathrm{G}$ protein-like partner at the intracellular site.

(b) Changes in isoprenaline affinity of $\beta_{1} \mathrm{AR}$ induced by NB80 binding. The isoprenaline affinity was assayed for TS- $\beta_{1} \mathrm{AR}_{\mathrm{A} 227 \mathrm{Y} / \mathrm{L343Y}}$ (green) and the truncated native turkey $\beta_{1} \mathrm{AR}$ receptor $(\mathrm{t} \beta \text { trunc, blue })^{17}$ by radio-ligand competition using ${ }^{3} \mathrm{H}$-dihydroalprenolol in the

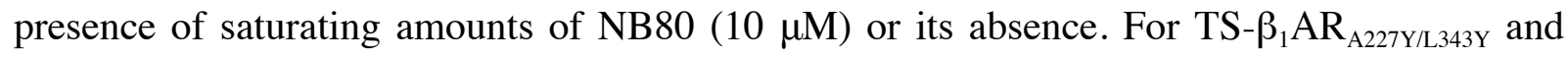
t $\beta$ trunc the apparent affinity increases by two log units in the presence of NB80, whereas no change occurs for TS- $\beta_{1}$ AR. Data points are shown as mean and standard deviation of three independent experiments for each condition.

(c) Combined ${ }^{1} \mathrm{H}$ and ${ }^{15} \mathrm{~N}$ chemical shift changes $\left(\Delta \delta=\left(\Delta \delta_{1 \mathrm{H}}{ }^{2} / 2+\Delta \delta_{15 \mathrm{~N}}{ }^{2} / 50\right)^{1 / 2}\right)$ between the isoprenaline-TS- $\beta_{1} \mathrm{AR}_{\mathrm{A} 227 \mathrm{Y} / \mathrm{L} 343 \mathrm{Y}}$ and the NB80-isoprenaline-TS- $\beta_{1} \mathrm{AR}_{\mathrm{A} 227 \mathrm{Y} / \mathrm{L} 343 \mathrm{Y}}$ complexes as a function of residue number. Except for the few assigned peaks in the NB80-isoprenaline-TS$\beta_{1} \mathrm{AR}_{\mathrm{A} 227 \mathrm{Y} / \mathrm{L} 343 \mathrm{Y}}$ complex, chemical shift deviations are calculated as the minimal difference from the isoprenaline peak position to the nearest peak position in the isoprenaline-NB80 complex. Note that these minimal chemical shift deviations present a lower boundary for the deviations that could be obtained from a full assignment of the isoprenaline-NB80 complex. Peak deviations are color-coded in red $(\geq 0.2 \mathrm{ppm})$, orange $(0.2-0.05 \mathrm{ppm})$, blue $(<0.05 \mathrm{ppm})$, and grey (ambiguity from peak overlap).

(d) Representation of the chemical shift response to nanobody binding given in (c) on the structure of $\beta_{1}$ AR. Valines in TM1 and TM7 do not show a large chemical shift response. Due to overlap the response for V280(6.25) in TM6 is unclear. Valines in TM2 show a strong response around the sodium binding region near residue D87(2.50), but valines at its extracellular side are not responsive. In general, valine resonances at the extracellular sides of TM3-6 are severely shifted. This indicates that the NB80 binding at the intracellular side has a long-range effect on the extracellular side, near the ligand binding site. 
Extended Data Table 1: Pharmacological and geometrical properties of the $\beta_{1} A R$ ligands used in this study

\begin{tabular}{|c|c|c|c|c|c|c|}
\hline & \multicolumn{4}{|c|}{ pharmacology } & \multicolumn{2}{|c|}{ geometry } \\
\hline & $\begin{array}{c}\mathrm{p} K_{D} \\
\text { b36-m23* }\end{array}$ & $\begin{array}{c}\mathrm{p} K_{i} \\
\mathrm{TS}-\beta_{1} \mathrm{AR}^{\dagger}\end{array}$ & $\begin{array}{c}\mathrm{p} / C_{50} \\
\mathrm{TS}-\beta_{1} \mathrm{AR}^{\sharp}\end{array}$ & $\begin{array}{c}\text { Gs efficacy } \\
t \beta \text { trunc }^{\S}\end{array}$ & $\begin{array}{l}\text { insertion } \\
\text { depth }\end{array}$ & tail volume \\
\hline cyanopindolol & $10.01 \pm 0.11$ & $>8.4 \pm 0.3^{\#}$ & $>8.1 \pm 0.1^{\#}$ & $39 \pm 1$ & 7.22 & 90.11 \\
\hline carvedilol & $8.72 \pm 0.09$ & $>8.3 \pm 0.3^{\#}$ & $>7.9 \pm 0.1^{\#}$ & $12 \pm 0.4$ & 7.62 & 163.47 \\
\hline alprenolol & $7.35 \pm 0.07$ & $7.6 \pm 0.3$ & $7.2 \pm 0.1$ & $31 \pm 2$ & 7.25 & 73.87 \\
\hline dobutamine & $5.49 \pm 0.03$ & $5.0 \pm 0.3$ & $4.6 \pm 0.1$ & $112 \pm 7$ & 8.46 & 170.34 \\
\hline isoprenaline & $5.16 \pm 0.05$ & $4.9 \pm 0.3$ & $4.6 \pm 0.2$ & 100 & 7.92 & 73.87 \\
\hline atenolol & $4.29 \pm 0.11$ & $5.0 \pm 0.3$ & $4.6 \pm 0.2$ & $2.1 \pm 1$ & ND & 73.87 \\
\hline
\end{tabular}

*Values for binding affinity correspond to the $\beta 36-\mathrm{m} 23$ construct, which contains $\mathrm{C}$ - and Nterminal deletions and six thermostabilizing mutations ${ }^{10}$. The $\mathrm{p} K_{D}=-\log K_{D}[\mathrm{M}]$ was obtained from ${ }^{3} \mathrm{H}$-CGP12177 whole cell binding assays in stably expressed $\mathrm{CHO}$ cells ${ }^{17}$.

${ }^{\dagger} \mathrm{p} K_{i}$ values were obtained from the $\mathrm{p} I C_{50}$ values given in column 3 by adding $\log \left(1+[\operatorname{lig}] / K_{D}\right)$ $=0.366$ as a correction for the concentration of the ${ }^{3} \mathrm{H}$-dihydroalprenolol $\left({ }^{3} \mathrm{H}-\mathrm{DHA}\right)([\mathrm{lig}]=$ $20 \mathrm{nM})$ and its determined dissociation constant $\left(K_{D}=15.1 \pm 7 \mathrm{nM}\right.$, see Methods). Errors are obtained by error propagation from the errors of the $\mathrm{p} I C_{50}$ values and $K_{D}$.

${ }^{*} \mathrm{p} I C_{50}$ values were determined by the radioligand inhibition assay described in the Methods section using ${ }^{3} \mathrm{H}-\mathrm{DHA}$. Data are given as mean and standard deviation of three independent experiments.

$\S$ Values for efficacy towards Gs-mediated signaling as determined by adenylyl cyclase activation of the truncated native turkey $\beta_{1} \mathrm{AR}$ receptor $(t \beta \text { trunc })^{17}$. The efficacies are indicated as the percentage of the (maximal) isoprenaline response obtained from ${ }^{3} \mathrm{H}$-cAMP accumulation assays in $\mathrm{CHO}$ cells.

"The insertion depth $[\AA]$ of the ligand was taken as the distance between the $\beta$-carbon atom of the ligand amino group and the amide nitrogen atom of V125 (V117 for $\beta_{2} \mathrm{AR}$ ) in the crystal structures of turkey $\beta_{1} \mathrm{AR}$ in complexes with isoprenaline (PDB ID: $2 \mathrm{Y03}$ ), dobutamine (PDB ID: 2Y00), carvedilol (PDB ID: 4AMJ), and cyanopindolol (PDB ID: 4BVN) as well as of human $\beta_{2} \mathrm{AR}$ in complex with alprenolol (PDB ID: 3NYA).

I The tail volumes $\left[\AA^{3}\right]$ were calculated by the Molinspiration Property Calculation Service (http://www.molinspiration.com/cgi-bin/properties) for the tail group including the amino moiety.

${ }^{\#}$ The $\mathrm{p} K_{i}$ and $\mathrm{p} I C_{50}$ are limited by the $K_{D}$ and concentration of the radioactive tracer ligand as well as by the concentration of the receptor in the competition assay.

Not determined, no crystal structure available. 
Extended Data Table 2: Sequence-specific assignment ${ }^{1} \mathrm{H}^{15} \mathrm{~N}$ valine resonances

\begin{tabular}{lllll}
\hline $\begin{array}{c}\text { Assigned } \\
\text { residue }\end{array}$ & Position & $\begin{array}{c}\text { Point } \\
\text { mutation }\end{array}$ & Spectra with ligands & $\begin{array}{c}\text { Further } \\
\text { information }\end{array}$ \\
\hline V62 & 1.53 & V62A & Ate, Apo, Alp & HN(CO) \\
V90 & 2.53 & V90A & Ate, Alp, Car, Cya & \\
V94 & 2.56 & V94A & Alp, Car, Cya & \\
V102 & 2.54 & V102A & Ate, Apo, Alp, Iso, Dob, Car, Cya & \\
V122 & 3.33 & V122A & Alp, Car, Cya & \\
V125 & 3.36 & V125A/l & Alp(A), Car(A), Ate(I), Apo(I) & \\
V129 & 3.40 & V129l & Ate & \\
V134 & 3.45 & V134A & Ate & Pred \\
V160 & 4.44 & V160A & Ate & Pred \\
V172 & 4.56 & V172A & Ate, Alp & \\
V202 & ECL & V202A & Alp & HN(CO) \\
V226 & 5.57 & V226A & Alp, Car, Cya & \\
V230 & 5.61 & V230A & Alp & HB, NM \\
V280 & 6.25 & V280A & Alp, Car, Cya & HB, NM, HN(CO) \\
V298 & 6.43 & V298A & Ate & HB, NM, HN(CO) \\
V314 & 6.59 & V314A & Alp, Car, Cya & NM \\
V326 & 7.36 & V326A & Alp & \\
V89 & 2.52 & - & Ate, Apo, Alp, Iso, Dob, Car, Cya & \\
V95 & 2.57 & - & Ate, Apo, Alp, Iso, Dob, Car, Cya & \\
V103 & 2.65 & - & Ate, Apo, Alp, Iso, Dob, Car, Cya & \\
V165 & 4.49 & - & Ate, Apo, Alp, Iso, Dob, Car, Cya & \\
\hline
\end{tabular}

Ate: atenolol, Alp: alprenolol, Iso: isoprenaline, Dob: dobutamine, Car: carvedilol, Cya: cyanopindolol

$\mathrm{HN}(\mathrm{CO})$ : information from 2D-filtered $\mathrm{HN}(\mathrm{CO})$ of ${ }^{15} \mathrm{~N},{ }^{13} \mathrm{C}-\mathrm{Gly}, \mathrm{Val},{ }^{15} \mathrm{~N}-$ Leu labeled receptor Pred: ShiftX $2{ }^{15} \mathrm{~N}$ chemical shift prediction ${ }^{31}$

HB: expected ${ }^{1} \mathrm{H}^{\mathrm{N}}$ shift based on hydrogen bond length analysis

NM: peak shift due to mutation of neighboring residue

Assignments for V89(2.52), V95(2.57), V103(2.65), V122(3.33), and V165(4.49) are tentative. V51(1.42), V52(1.43), V56(1.47), V60(1.51), V309(6.54), V312(6.57), and V320(ECL) have not been assigned. 
Extended Data Table 3: Summary of the NMR response to ligands, G protein activation and NB80 binding data for the original TS- $\beta_{1} A R$ construct and various reverse mutants towards the native $\beta_{1} A R$ sequence

\begin{tabular}{|c|c|c|c|c|c|c|c|c|}
\hline \multirow{2}{*}{ mutant name } & \multicolumn{3}{|c|}{ residue } & \multirow{2}{*}{$\begin{array}{c}\text { V226 } \\
\text { response* }\end{array}$} & \multirow{2}{*}{$\begin{array}{c}\text { V280 } \\
\text { response* }\end{array}$} & \multirow{2}{*}{$\begin{array}{l}\text { G protein } \\
\text { activation }^{\dagger}\end{array}$} & \multirow{2}{*}{$\begin{array}{c}\text { NB80 } \\
\text { binding }\end{array}$} & \multirow{2}{*}{$\mathrm{T}_{\mathrm{m}}\left[{ }^{\circ} \mathrm{C}\right]^{\S}$} \\
\hline & 129 & 227 & 343 & & & & & \\
\hline original TS- $\beta_{1} A R$ & V & A & L & + & - & - & $\begin{array}{c}- \\
(4.55 / 4.52)\end{array}$ & $58.9+/-0.6$ \\
\hline $\mathrm{TS}-\beta_{1} \mathrm{AR}_{\mathrm{V} 1291}$ & $I^{\prime \prime}$ & A & L & + & - & - & N.D." & $58.6+/-0.2$ \\
\hline $\mathrm{TS}-\beta_{1} \mathrm{AR}_{\mathrm{A} 22 \mathrm{Y} Y}$ & V & $\mathbf{Y}$ & L & + & - & - & - & $54.9+/-0.1$ \\
\hline $\mathrm{TS}-\beta_{1} \mathrm{AR}_{\mathrm{L} 343 \mathrm{Y}}$ & V & A & $\mathbf{Y}$ & + & - & - & - & $54.7+/-0.3$ \\
\hline$T S-\beta_{1} A R_{V 1291 / A 227 Y}$ & I & $\mathbf{Y}$ & L & + & - & - & N.D. & $54.4+/-0.1$ \\
\hline$T S-\beta_{1} A R_{A 227 Y / L 343 Y}$ & V & $\mathbf{Y}$ & $\mathbf{Y}$ & + & - & + & $\begin{array}{c}+ \\
(4.36 / 6.32)\end{array}$ & $47.8+/-0.2$ \\
\hline
\end{tabular}

* determined from the shifts of the ${ }^{1} \mathrm{H}_{-}{ }^{15} \mathrm{~N}$ resonances in response to binding of atenolol and isoprenaline (see Extended Data Figure 6B).

${ }^{\dagger}$ determined from the Gai1 $\beta 1 \gamma 1$ activation assay described in Extended Data Figure 5.

$¥$ determined from NMR experiments by mixing of isoprenaline-activated TS- $\beta_{1}$ AR with NB80. The ${ }^{1} \mathrm{H}_{-}{ }^{15} \mathrm{~N}$ spectra are shown for $\mathrm{TS}-\beta_{1} \mathrm{AR}_{\mathrm{A} 227 \mathrm{Y} / \mathrm{L} 343 \mathrm{Y}}$ in Extended Data Figure 7 . The spectra of the other TS- $\beta_{1}$ AR mutants showed no response to addition of NB80 up to equimolar concentrations of $\sim 100 \mu \mathrm{M}$ for both proteins. Values in parentheses show $\mathrm{p} I C_{50}$ for isoprenaline binding in the absence or presence of NB80, respectively (see Extended Data Figure 7).

${ }^{\S}$ melting temperature $T_{m}$ of the apo form receptor determined by the CPM thermal shift assay.

" native residues are highlighted in bold.

Is not determined. 
a
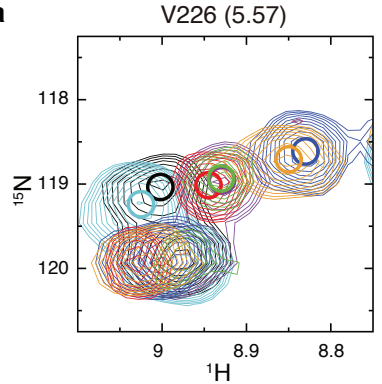

b

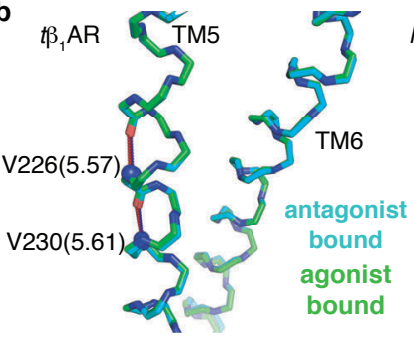

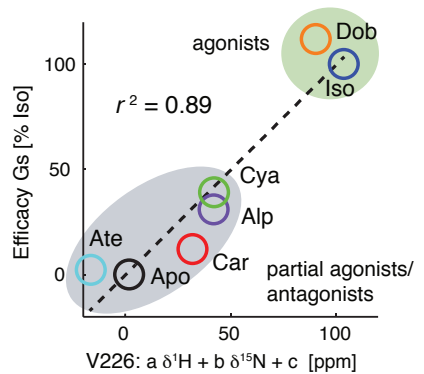

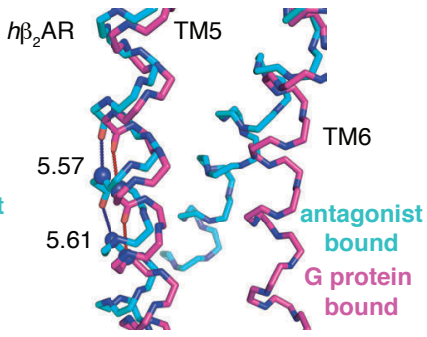

C

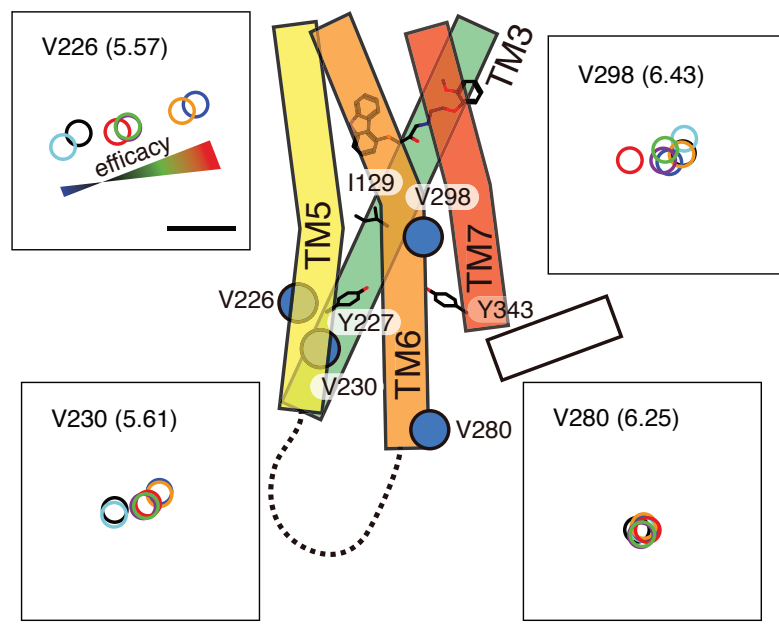

Figure 2 


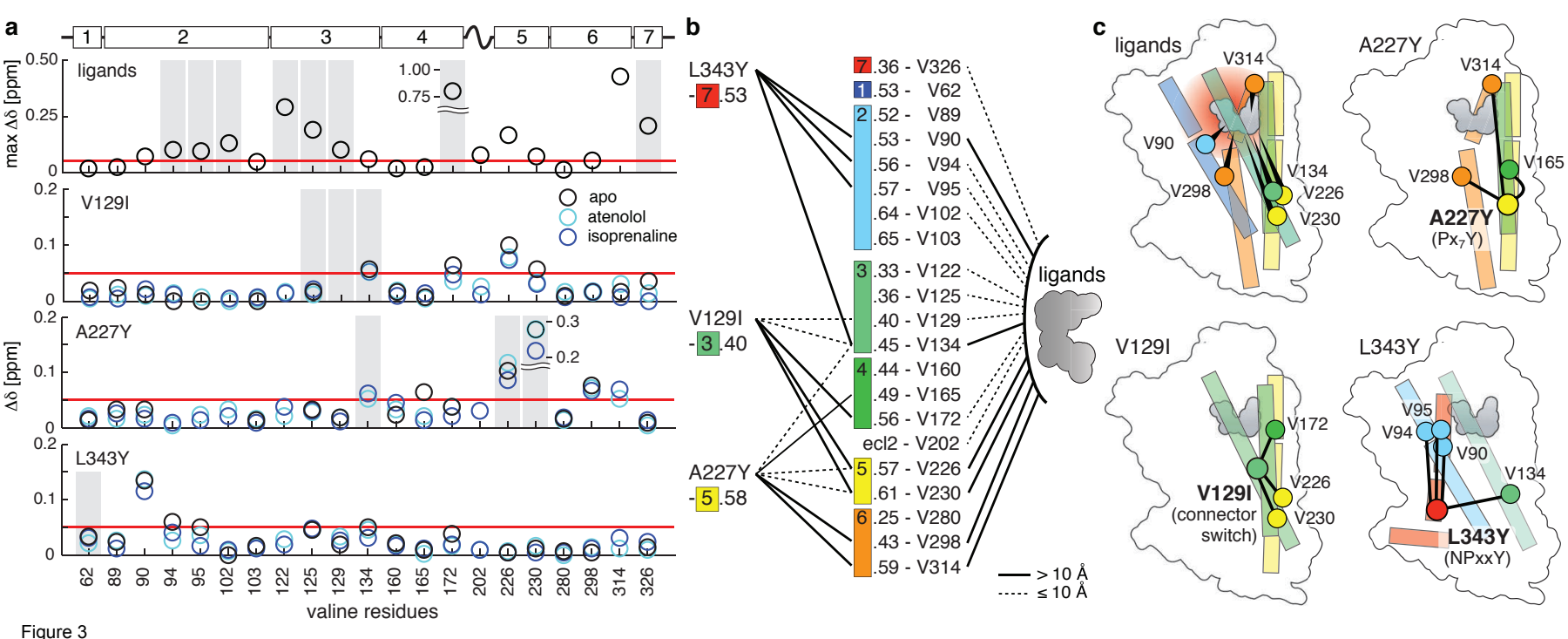



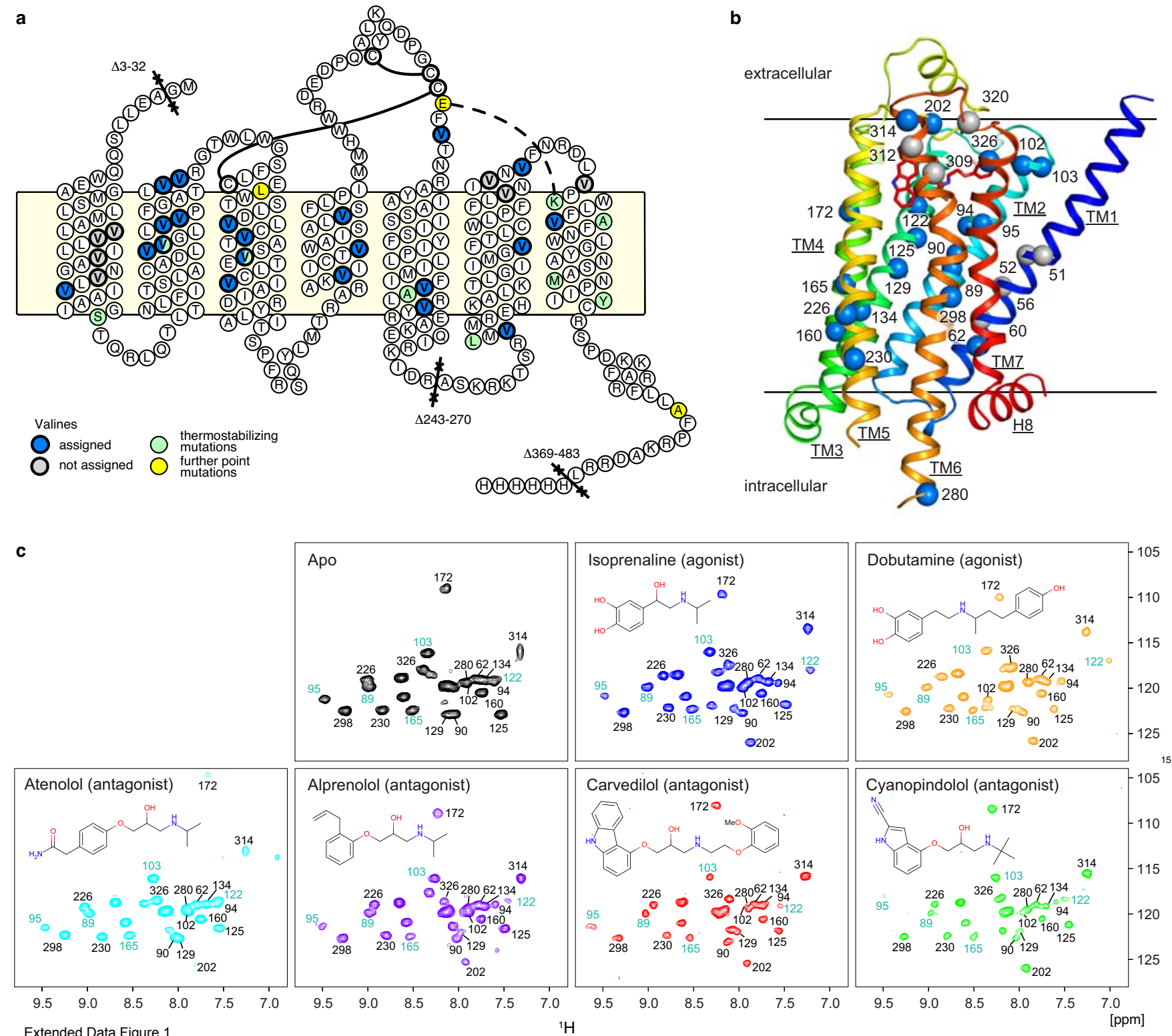

Extended Data Figure 1

Alprenolol (antagonist)

172

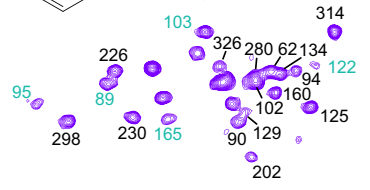

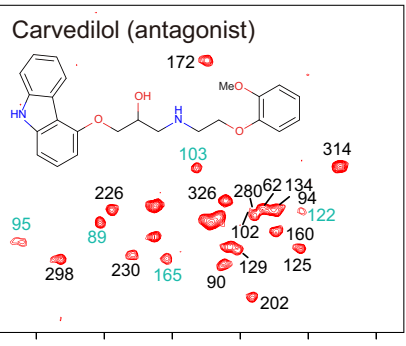

Carvedilol (antagonist)
${ }^{5} \mathrm{~N}$

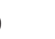

$H$ 
$\begin{array}{lll}4.50 & 4.56 \quad 4.60\end{array}$

tADRB1 TVWA ISALVSFLP I hADRB1 TVWAISALVSFLPI hADRB2 MVWIVSGLTSFLPI hADRB3 LVWVVSAAVSFAPI hADRA1A LLWVVALVVSVGPL hADRA2A TVWVISAVISFPPL hADRA2B TVWLIAAVISLPPL hADRA2C AVWLISAVISFPPL consensus $\mathrm{VWi}$ isalvSf $\mathrm{Pi}$ b

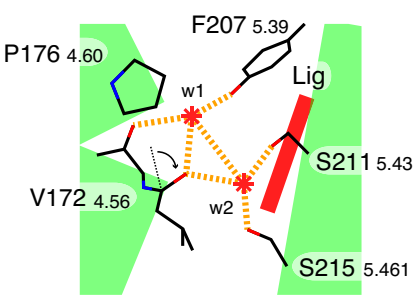

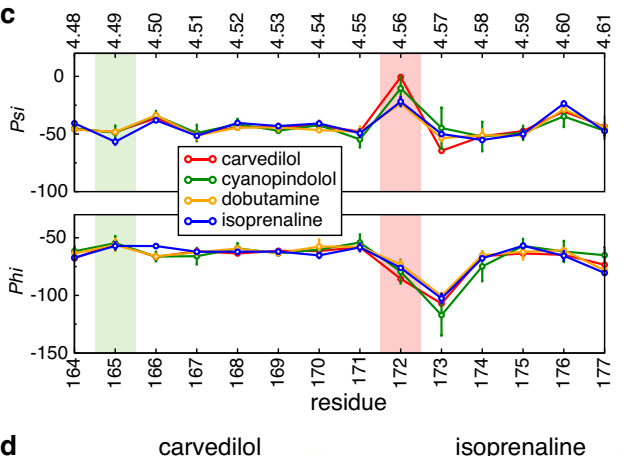

carvedilol

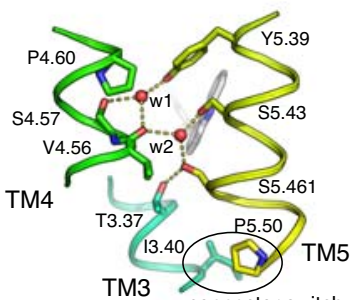

Extended Data Figเ中@ngector switch

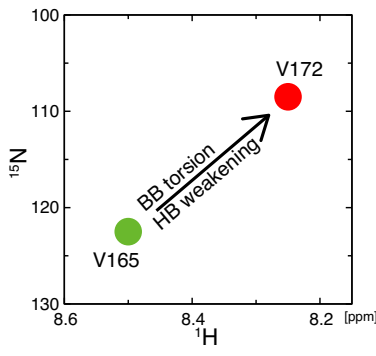

atenolol
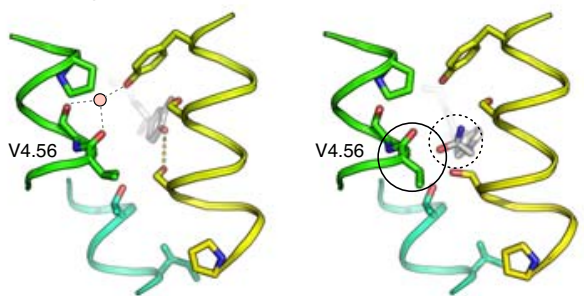


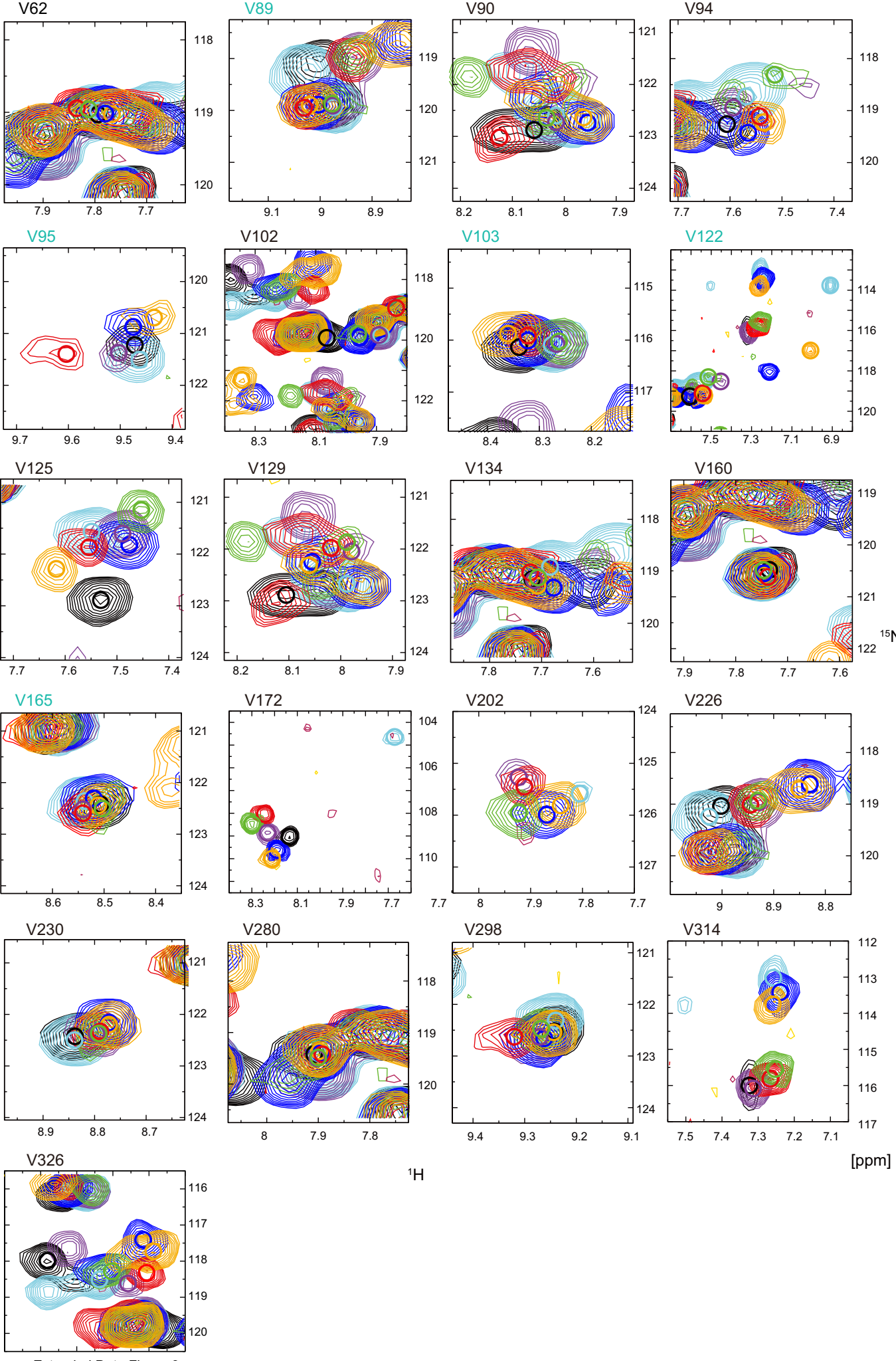




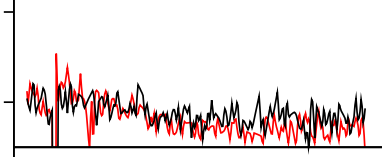

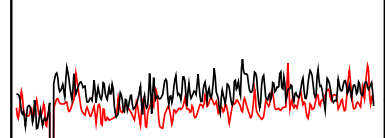
A227Y

\section{L343Y}

1.1

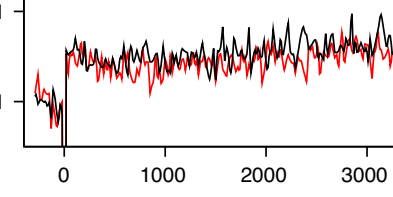

Extended Data Figure 5 time [s] 


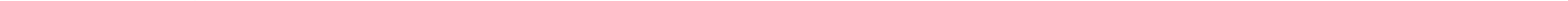




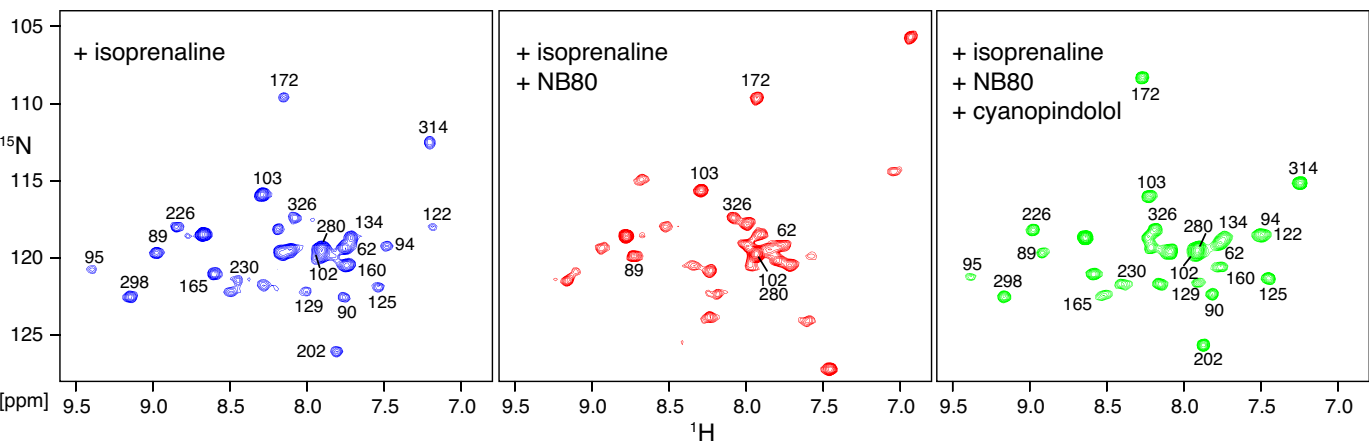

b
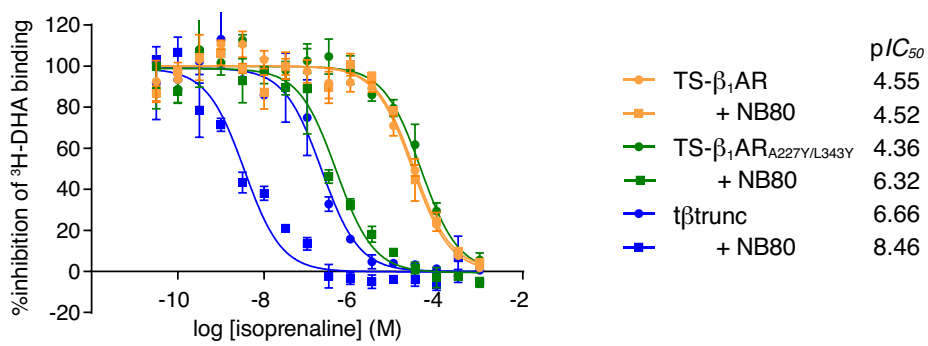

c

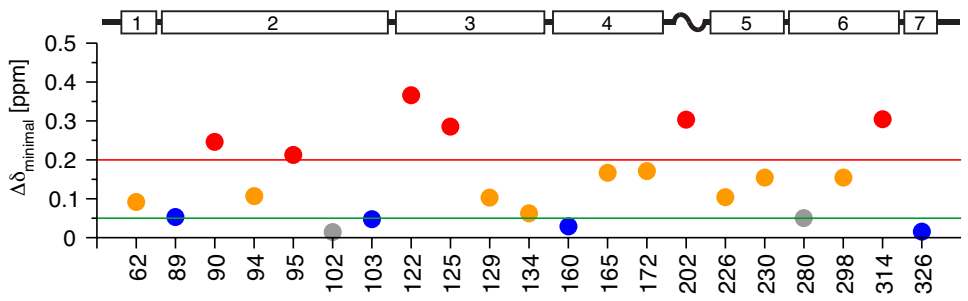

d

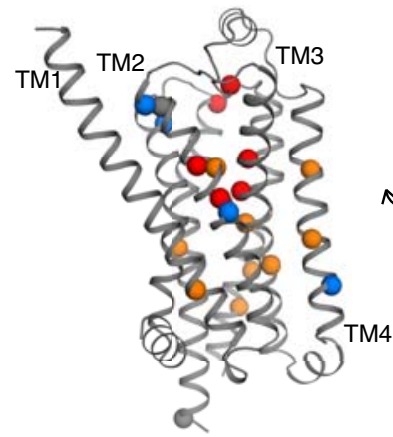

residue

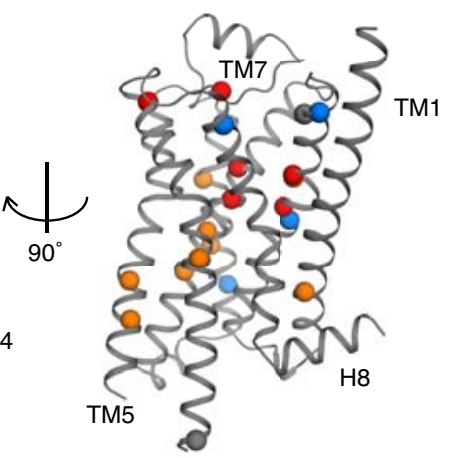




\section{Backbone NMR reveals allosteric signaling networks in the $\beta_{1}$-adrenergic receptor}

\section{Supplementary Information}

Shin Isogai ${ }^{1}$, Xavier Deupi ${ }^{2}$, Christian Opitz ${ }^{1}$, Franziska M. Heydenreich ${ }^{2}$, Ching-Ju Tsai $^{2}$, Florian Brueckner ${ }^{2}$, Gebhard F.X. Schertler ${ }^{2,3 *}$, Dmitry B. Veprintsev ${ }^{2,3 *}$ and Stephan Grzesiek ${ }^{1, *}$

${ }^{1}$ Focal Area Structural Biology and Biophysics, Biozentrum, University of Basel, CH-4056 Basel, Switzerland

${ }^{2}$ Paul Scherrer Institute, CH-5232 Villigen PSI, Switzerland

${ }^{3}$ Department of Biology, ETH Zurich, CH-8093 Zurich, Switzerland

*corresponding authors

Stephan Grzesiek

Focal Area Structural Biology and Biophysics, Biozentrum

University of Basel, CH-4056 Basel, Switzerland

Phone: $\quad++41612672100$

FAX: $\quad++41612672109$

Email: Stephan.Grzesiek@unibas.ch

Dmitry B. Veprintsev

Paul Scherrer Institute, CH-5232 Villigen PSI, Switzerland

Email: dmitry.veprintsev@psi.ch

Gebhard F.X. Schertler

Paul Scherrer Institute, CH-5232 Villigen PSI, Switzerland

Email: gebhard.schertler@psi.ch 


\section{Text 1. Estimation of hydrogen bond length change from ${ }^{1} H^{N}$ chemical shift change and uncertainty of crystal structure coordinates}

The correlation between hydrogen bond length $d_{H O}$ and amide proton chemical shift $\delta H^{N}$ can be expressed as ${ }^{1}$

$$
\delta H^{N}=19.2 \cdot \AA^{3} \cdot d_{H O}^{-3}-2.3
$$

where $\delta H^{N}$ is given in ppm and $d_{H O}$ is the distance between amide hydrogen and carbonyl oxygen atoms. Taking the derivative relative to the distance $d_{H O}$ yields

$$
\frac{d \delta H^{N}}{d d_{H O}}=-3 \cdot 19.2 \cdot \AA^{3} \cdot d_{H O}^{-4}
$$

A finite small change $\Delta d_{H O}$ in hydrogen bond distance can then be calculated from a finite small chemical shift change $\Delta \delta H^{N}$ as

$$
\Delta d_{H O} \approx \frac{-d_{H O}^{4}}{3 \cdot 19.2 \cdot \AA^{3}} \Delta \delta H^{N}
$$

Using $\Delta \delta H^{N}=-0.2$ for the change from the atenolol-bound to the isoprenaline-bound V226 resonances and $d_{\mathrm{HO}}=1.9 \AA$ then yields a value $\Delta d_{\mathrm{HO}}=0.045 \AA$.

The uncertainty of crystal structure coordinates can be estimated from the Cruickshank diffraction-component precision index (DPI ${ }^{2}$. For the currently highest resolution GPCR structure (human $\delta$ opioid receptor $^{3}, 1.80 \AA$ resolution), the DPI is $0.127 \AA$, which is larger than the small H-bond distance change detected by NMR.

\section{References}

1. Grzesiek, S., Cordier, F., Jaravine, V. \& Barfield, M. Insights into biomolecular hydrogen bonds from hydrogen bond scalar couplings. Prog Nucl Mag Res Sp 45, 275-300 (2004).

2. Cruickshank, D. W. J. Remarks about protein structure precision. Acta Crystallogr D Biol Crystallogr 55, 583-601 (1999).

3. Fenalti, G. et al. Molecular control of $\delta$-opioid receptor signalling. Nature 506, 191-196 (2014). 